\title{
Modeling the impact of iron and phosphorus limitations on nitrogen fixation in the Atlantic Ocean
}

\author{
V. J. Coles and R. R. Hood \\ Horn Point Laboratory, University of Maryland Center for Environmental Science, P.O. Box 775, 2020 Horns Point Road, \\ Cambridge, MD, 21613 USA
}

Received: 27 June 2006 - Published in Biogeosciences Discuss.: 21 September 2006

Revised: 26 April 2007 - Accepted: 23 May 2007 - Published: 6 July 2007

\begin{abstract}
The overarching goal of this study is to simulate subsurface N* (sensu, Gruber and Sarmiento, 1997; GS97) anomaly patterns in the North Atlantic Ocean and determine the basin wide rates of $\mathrm{N}_{2}$-fixation that are required to do so. We present results from a new Atlantic implementation of a coupled physical-biogeochemical model that includes an explicit, dynamic representation of $\mathrm{N}_{2}$-fixation with light, nitrogen, phosphorus and iron limitations, and variable stoichiometric ratios. The model is able to reproduce nitrogen, phosphorus and iron concentration variability to first order. The latter is achieved by incorporating iron deposition directly into the model's detrital iron compartment which allows the model to reproduce sharp near surface gradients in dissolved iron concentration off the west coast of Africa and deep dissolved iron concentrations that have been observed in recent observational studies. The model can reproduce the large scale $\mathrm{N}^{*}$ anomaly patterns but requires relatively high rates of surface nitrogen fixation to do so $\left(1.8 \times 10^{12}\right.$ moles $\mathrm{N} \mathrm{yr}^{-1}$ from $10^{\circ} \mathrm{N}-30^{\circ} \mathrm{N}$, $3.4 \times 10^{12}$ moles $\mathrm{N} \mathrm{yr}^{-1}$ from $25^{\circ} \mathrm{S}-65^{\circ} \mathrm{N}$ ). In the model the surface nitrogen fixation rate patterns are not co-located with subsurface gradients in $\mathrm{N}^{*}$. Rather, the fixed nitrogen is advected away from its source prior to generating a subsurface $\mathrm{N}^{*}$ anomaly. Changes in the phosphorus remineralization rate (relative to nitrogen) linearly determine the surface nitrogen fixation rate because they change the degree of phosphorus limitation, which is the dominant limitation in the Atlantic in the model. Phosphorus remineralization rate must be increased by about a factor of 2 (relative to nitrogen) in order to generate subsurface $\mathrm{N}^{*}$ anomalies that are comparable to the observations. We conclude that $\mathrm{N}_{2}$-fixation rate estimates for the Atlantic (and globally) may need to be revised upward, which will help resolve imbalances in the
\end{abstract}

Correspondence to: V. J. Coles

(vcoles@hpl.umces.edu) global nitrogen budget suggested by Codispoti et al. (2001) and Codispoti (2007).

\section{Introduction}

Oceanic uptake of anthropogenic $\mathrm{CO}_{2}$ is driven by a combination of physical processes, i.e., the "solubility pump" (Doney et al., 2004), and biologically mediated uptake, i.e., the "biological pump" (Sarmiento and Bender, 1994). In a steady-state ocean where biogeochemical cycling occurs in Redfield proportions (Redfield et al., 1963), biologicallydriven export does not result in a significant net carbon export to the deep ocean (Broecker, 1991). However, there are two very important processes in the ocean that can result in nonRedfield elemental cycling and net carbon export. These are atmospheric dinitrogen $\left(\mathrm{N}_{2}\right)$ fixation and denitrification. In regions where carbon fixation and export are limited by the availability of nitrogen $(\mathrm{N})$, the addition of fixed $\mathrm{N}$ from the atmosphere due to $\mathrm{N}_{2}$-fixation can allow carbon fixation to proceed and a net carbon export can result. Estimates suggest that this process can drive a significant fraction of the total, global carbon export (Hood et al., 2000). The removal of $\mathrm{N}$ from the ocean due to denitrification has the opposite effect. Thus, it may be very important to represent the impact of these processes in prognostic regional and global ocean carbon cycle models. However, the magnitudes of these sources and sinks are still poorly constrained by observations (Codispoti et al., 2001; Gruber and Sarmiento, 2002; Capone et al., 2005; Codispoti, 2007; Gruber, 2006). Because nitrogen fixation and denitrification determine the total fixed nitrogen inventory in the oceans both locally (on seasonal and annual timescales) and globally (on geological timescales) they also determine the degree to which the oceans are either nitrogen or phosphorus limited (Tyrrell, 1999).

Published by Copernicus Publications on behalf of the European Geosciences Union. 
The factors that control pelagic nitrogen fixation are still not fully understood. Rueter (1982) and Rueter et al. (1992) argued that iron $(\mathrm{Fe})$ is a primary factor limiting $\mathrm{N}_{2}$-fixation due to the high Fe requirement of the nitrogenase enzyme. This idea is supported by the early experimental work of Paerl et al. (1994) and the general global correspondence between regions of high iron/dust deposition and high $\mathrm{N}_{2}$-fixation, e.g., $\mathrm{N}_{2}$-fixation rates are generally higher in the Atlantic than in the Pacific (Capone et al., 1997; but see also Deutsch et al., 2006). Similarly, Walsh and Steidinger (2001) argue that $\mathrm{Fe}$ deposition events stimulate Trichodesmium blooms and $\mathrm{N}_{2}$-fixation in the Gulf of Mexico. In contrast, the in situ stoichiometric studies of SañudoWilhelmy et al. (2001) suggest that phosphorus (P) limits Trichodesmium growth and $\mathrm{N}_{2}$-fixation in the central north Atlantic. The potential for P limitation is supported by the fact that inputs of $\mathrm{N}$ to the surface ocean due to $\mathrm{N}_{2}$-fixation are not accompanied by a stoichiometric equivalent input of $\mathrm{P}$. Thus, $\mathrm{N}_{2}$-fixation tends to increase the N:P ratio in the water which leads to phosphorus limitation. It appears that these conflicting results have been reconciled at some level by Mills et al. (2004) who showed that Fe and P co-limit nitrogen fixation in the eastern tropical Atlantic, implying that both $\mathrm{P}$ and Fe limitations can be important, and that switching from one to another will likely occur depending upon local availability and recycling of Fe and P. Finally, it should also be noted that light availability and temperature are clearly important factors controlling $\mathrm{N}_{2}$-fixation (Capone et al., 1997; Coles et al., 2004; Hood et al., 2004), i.e., significant rates are observed only in warm tropical and subtropical waters and generally under stratified conditions where mean irradiance levels in the mixed layer are very high.

Only a handful of modeling studies have been undertaken that include explicit representations of $\mathrm{N}_{2}$-fixation along with N, P and/or Fe limitations. Tyrrell (1999) developed a simplified box model with both nitrogen and phosphorus cycling where the $\mathrm{N}_{2}$-fixation rate is a function of the supply ratio of inorganic nitrogen and phosphorus. In a three-dimensional model developed by Neumann (2000) $\mathrm{N}_{2}$-fixation rate depends upon phosphorus supply, temperature and irradiance. The models of Tyrrell (1999) and Neumann (2000) can distinguish between nitrogen and phosphorus control of phytoplankton and diazotroph growth. However, both assume a fixed Redfield stoichiometry. In contrast, Fennel et al. (2002) developed a 1-dimensional model with $\mathrm{N}_{2}$-fixation and both $\mathrm{N}$ and $\mathrm{P}$ limitations that allows for different stoichiometric ratios in different organic matter compartments (i.e., high N:P ratio for diazotrophs) and differential export of $\mathrm{N}$ and $\mathrm{P}$ from the upper ocean. However, they did not provide a mechanism for enhancing phosphorus supply to the surface. As a result, the diazotrophs in this model form a subsurface maximum associated with the phosphocline rather than growing near the surface. In a series of related global modeling efforts Moore et al. (2002a; 2002b), Moore et al. (2004) and Moore et al. (2007) included dia- zotrophs in a multi-species, multi-element biogeochemical model with $\mathrm{N}, \mathrm{P}$ and Fe limitations. The large-scale spatial patterns of diazotroph biomass and $\mathrm{N}_{2}$-fixation in these studies suggest that they are determined primarily by mixed-layer depth and light, and/or temperature. However, these studies also suggest widespread $\mathrm{Fe}$ and $\mathrm{P}$ limitation, with the latter particularly pronounced in the Atlantic in Moore et al. (2004) where the N/P ratio is fixed.

Clearly, there are some important questions that have not been fully addressed with these models. The fact that $\mathrm{N}_{2}$ fixation naturally leads to $\mathrm{P}$ limitation presents a serious dilemma in modeling studies, i.e., some means of supplying a stoichiometric equivalent amount of $\mathrm{P}$ to near-surface waters must be invoked in models in order to allow $\mathrm{N}_{2}$-fixation to proceed at significant rates. This problem becomes particularly significant if one attempts to reproduce the high rates of pelagic $\mathrm{N}_{2}$-fixation that have been reported in recent studies and synthesis papers (GS97; Gruber and Sarmiento, 2002; Capone et al., 2005; Gruber, 2006). One potential mechanism for supplying additional phosphorus to the surface is "phosphorus mining", i.e., the idea that large diazotrophs like Trichodesmium can migrate down to the phosphocline periodically to satisfy their phosphorus requirement (Karl et al., 1992). Another, perhaps more likely, mechanism is that phosphorus availability can be maintained at the surface to support diazotrophic growth by simply recycling it faster than nitrogen (Wu et al., 2000; Hood et al., 2006). In addition, Dyhrman et al. (2006) has suggested that diazotrophs have access to dissolved organic phosphorus (DOP) pools that are not available to other phytoplankton species. However, none of these P supply mechanisms have been quantified (Hood et al., 2000).

Another important challenge is Fe-cycling. Many biogeochemical models that carry $\mathrm{Fe}$ do not produce realistic $\mathrm{Fe}$ profiles (e.g., Dutkiewicz et al., 2005; but see also Parekh et al., 2005). Finally, a major challenge that has not yet been fully addressed in prognostic modeling studies is whether or not it is possible to simultaneously reproduce observed surface distributions and rates of pelagic $\mathrm{N}_{2}$-fixation (Capone et al., 1997; Capone et al., 2005) and observed subsurface N:P ratio anomaly patterns (i.e., N*, Michaels et al., 1996; GS97; Hansell et al., 2004). This is a critical test for modeling because $\mathrm{N}^{*}$ provides a spatially and temporally integrating constraint on $\mathrm{N}_{2}$-fixation rate, export and relative recycling rates of $\mathrm{N}$ and P. Only a few prognostic modeling studies have attempted to reproduce observed $\mathrm{N}^{*}$ anomaly patterns (e.g., Moore and Doney, 2007) and none have done so in 3 dimensions.

In this paper we present results from a 3-dimensional, coupled, physical-biogeochemical model with a dynamic representation of $\mathrm{N}_{2}$-fixation that also includes $\mathrm{N}, \mathrm{P}$ and $\mathrm{Fe}$ mineral cycling and limitations. Our goal is to determine whether the 3-dimensional $\mathrm{N}^{*}$ patterns observed in the Atlantic (e.g., GS97) can be reproduced in a numerical model that includes an explicit, dynamic representation of nitrogen 
fixation, and whether the distribution and biomass of diazotrophs that gives rise to a reasonable $\mathrm{N}^{*}$ signal is consistent with observations (e.g., Carpenter and Romans, 1991). We also seek to assess the sensitivity of the modeled $\mathrm{N}^{*}$ distributions to the relative rates of detrital nitrogen and phosphorus $\left(D_{N}\right.$ and $\left.D_{P}\right)$ remineralization, and determine the degree to which the patterns of diazotroph biomass and nitrogen fixation rate are dependent on phosphorus and iron supply and distribution.

\section{The model}

\subsection{Biogeochemical model}

The biogeochemical model used in this study is a modified version of the Hood et al. (2001) model (see also Coles et al., 2004; Hood et al., 2004) that includes iron and phosphorus cycling and limitations (Fig. 1). Here we provide a general description of the model. The equations are presented in detail along with the parameter values and sources in Appendices $\mathrm{A}$ and $\mathrm{B}$, respectively.

The biogeochemical model is $\mathrm{N}$-based, and includes six essential components: Inorganic nutrients (DIN, DIP, DIFe), organic nutrients (DON, DOP, DOFe), detritus $\left(D_{N}\right.$, $\mathrm{D}_{\mathrm{P}}, \mathrm{D}_{\mathrm{Fe}}$ ), phytoplankton, a diazotroph patterned after Trichodesmium, and heterotrophs. The latter is intended to represent all heterotrophic processes, which are dominated by microbes (i.e., bacteria and protozoa). The phytoplankton, diazotroph, and heterotroph compartments have fixed stoichiometric ratios, but these ratios can be different from one another. In the simulations presented in this paper, phytoplankton and heterotrophs have Redfield P:N stoichiometry, whereas the diazotrophs are substantially more N-rich as observed (D. G. Capone, personal communication, Table A1). The Fe:N ratios for phytoplankton and heterotrophs were converted from published $\mathrm{Fe}: \mathrm{C}$ ratios for these groups (Tortell et al., 1999; Fung et al., 2000, respectively) using appropriate conversion factors. Diazotrophs were parameterized to have a substantially higher Fe: $\mathrm{N}$ ratio (and therefore $\mathrm{Fe}$ requirement) than phytoplankton or heterotrophs using conversion factors from Sañudo-Wilhelmy et al. (2001).

In contrast, the inorganic nutrient, organic nutrient and detritus compartments have variable stoichiometric ratios, which are determined by excretion and egestion by heterotrophs, exudation and mortality by and of phytoplankton, diazotrophs and heterotrophs, and remineralization of dissolved and particulate organic matter (DOM and POM). Remineralization of the DOM pools is driven by heterotrophmediated microbial consumption and degradation and also by direct remineralization to the dissolved inorganic nutrient pools. Heterotroph consumption rate is determined largely by biomass, which varies in space and time and it will lead to variable-ratio excretion and egestion if the heterotrophs consume organic matter that has a different stoichiometric

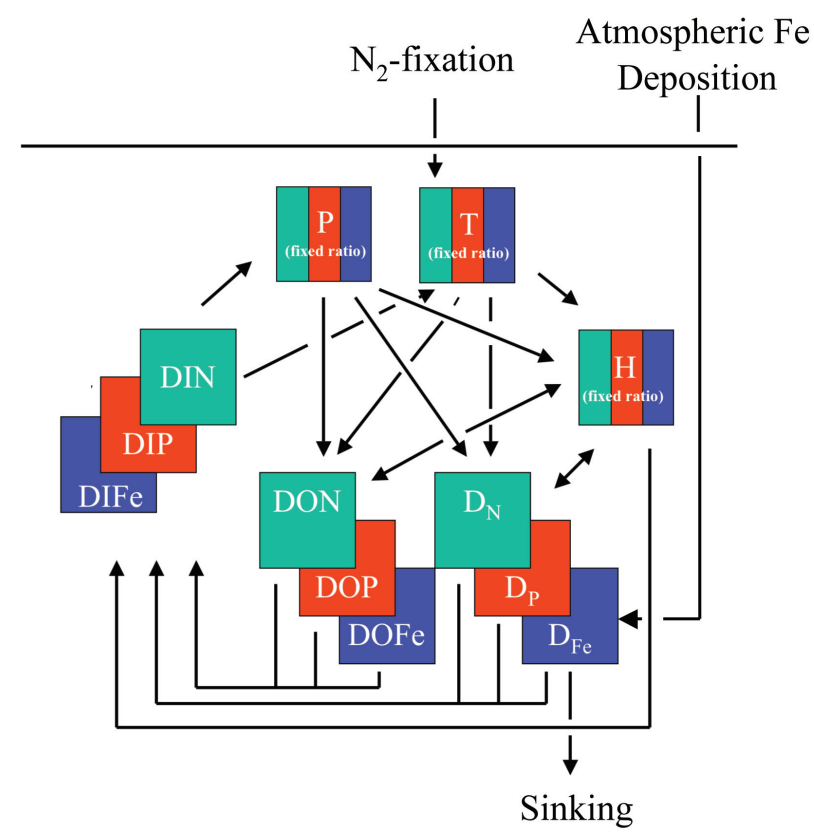

Fig. 1. Schematic diagram of the biogeochemical model with nitrogen fixation and $\mathrm{Fe}$ and $\mathrm{P}$ limitations. Single boxes with multiple colors represent model constituents with fixed elemental ratios, whereas compartments with multiple boxes represent model constituents with variable element ratios. DIX = dissolved inorganic nutrients, DOX is dissolved organic nutrients, DX is organic detritus, $\mathrm{P}$ is phytoplankton, $\mathrm{T}$ is Trichodesmium, and $\mathrm{H}$ is heterotroph.

ratio than its own mass. In contrast, remineralization of the POM pools is driven only by direct remineralization, which allows us to fully and independently control the remineralization length scales of sinking organic $\mathrm{D}_{\mathrm{N}}, \mathrm{D}_{\mathrm{P}}, \mathrm{D}_{\mathrm{Fe}}$. It is assumed that the remineralization rate of $\mathrm{P}>\mathrm{Fe}>\mathrm{N}$ for dissolved organic matter and detritus (Table A1). The specific remineralization rate values used for our main run solution (Table A1) were determined a posteriori, i.e., they were tuned to reproduce observed levels and patterns of $\mathrm{P}$ and $\mathrm{Fe}$ limitation as observed by Mills et al. (2004) and also to give reasonable concentrations at the surface and approximately correct $\mathrm{N}^{*}$ patterns. The degree of enhancement of $\mathrm{P}$ and $\mathrm{Fe}$ recycling relative to $\mathrm{N}$ that was required to achieve these solutions is discussed in Sect. 3.1.4 below.

Iron deposition at the surface mixed layer is specified using the model-generated climatological dust fluxes from Mahowald et al. (2003); Luo et al. (2003), which take into account both wet and dry deposition. It is assumed that a fraction of this dust is iron (Table A1) and that some fraction of this iron is bioavailable following previous modeling studies (Christian et al., 2002; Moore et al., 2002b, Table A1). This bioavailable fraction of the $\mathrm{Fe}$ is added directly to the $\mathrm{D}_{\mathrm{Fe}}$ compartment of the biogeochemical model. Fe is added to $\mathrm{D}_{\mathrm{Fe}}$ because it is assumed that further biological or chemical processing is required to make the dust associated iron 
available for uptake by phytoplankton. This assumption is made in part because vertical profiles of dissolved iron do not show a pronounced surface maximum as might be expected with a surface source function. Profiles do however show a maximum in particulate iron concentration at the surface with low dissolved iron concentrations at some stations in the tropical Atlantic, and the dissolved and particulate profiles converge near $100 \mathrm{~m}$ depth (Croot et al., 2004). Thus, adding $\mathrm{Fe}$ to $\mathrm{D}_{\mathrm{Fe}}$ gives much more realistic vertical DIFe profiles (subsurface maximum) compared to those that are obtained when Fe is by added directly to the DIFe pool (surface maximum). Following Christian et al. (2002b), Fe is "scavenged" from the DIFe pool at a rate that is proportional to the total detritus concentration (Eq. A22) using a scavenging rate specified in Table A1 and a non-dimensional multiplier specified in Eq. (A22). Our formulation differs from Christian et al. (2002b) in that we do not specify a maximum upper rate and we use a multiplier set to give $\mathrm{D}_{\text {tot }}\left(=\mathrm{D}_{\mathrm{N}}+\mathrm{D}_{\mathrm{P}}+\mathrm{D}_{\mathrm{Fe}}\right)$ concentrations that vary approximately between 0 and 1 . Although iron is not the only micro or macro nutrient in dust, we include only the term for iron deposition, i.e., we assume that the dust deposition rate is not sufficient to provide a significant flux of phosphorus or nitrogen relative to deep water sources.

\subsection{Physical model}

The 3-D general circulation model is the Hybrid Coordinate Ocean Model (HYCOM) (Bleck, 2002; Chassignet et al., 2003; Halliwell, 2004). This model is formulated with an arbitrary vertical coordinate that transitions from depth based coordinates at the surface to isopycnal layers in the ocean interior. (The model can also transition to sigma coordinate layers in coastal areas, however we have not used this feature in the simulations described in this paper.) This flexibility allows for enhanced vertical resolution in the mixed layer and euphotic zone while retaining the properties of an isopycnal model for advection of tracers in the ocean interior. Surface forcing occurs through momentum transfer from atmospheric winds, and thermodynamic fluxes of freshwater and heat with the uppermost model layer. Below the surface layer, advection and diffusion occur along isopycnal surfaces, with diapycnal mixing leading to an explicit exchange of mass and tracers between layers.

This Atlantic basin implementation stretches from $35^{\circ} \mathrm{S}$ to $65^{\circ} \mathrm{N}$ on a Mercator grid, with 24 vertical layers, and $2^{\circ}$ spatial resolution. The version is based on a similar Miami Isopycnal Coordinate Ocean Model implementation that has been shown to appropriately simulate Atlantic ecosystem and mixed layer dynamics (Coles et al., 2004; Hood et al., 2004). River runoff is incorporated in the simulations as precipitation, leading to a freshwater flux to the surface for the four largest Atlantic Basin rivers (Amazon, Congo, Orinocco, and Mississippi) with modest $\mathrm{P}$ and $\mathrm{Fe}$ concentrations of $0.4 \mathrm{mmol} / \mathrm{m}^{3}$ and $0.007 \mathrm{mmol} / \mathrm{m}^{3}$ respectively. At- mospheric forcing comes from the COADS dataset (da Silva et al., 1994), and surface salinity and temperature are relaxed back to the World Ocean Atlas 1994 (WOA94) monthly values to minimize model drift (Levitus and Boyer, 1994; Levitus et al., 1994).

The model is initialized and relaxed at the boundaries to the WOA94 temperature, salinity, nitrate, and phosphate (Conkright et al., 1994; Levitus and Boyer, 1994; Levitus et al., 1994). Initial DIFe is set proportionally to DIN using an Fe:DIN ratio of 25:1 ( $\mu \mathrm{mol}: \mathrm{mol})$ (c.f., Fung et al., 2000). The phytoplankton, diazotroph, heterotroph, DOM and Detrital pools are initialized at low and spatially uniform values using Redfield ratios for the DOM and Detrital pools. At the southern, northern and Mediterranean Sea boundaries the inorganic nutrient concentrations are relaxed below $25 \mathrm{~m}$ to seasonal averages. It is particularly important to initialize and relax to the observed nutrient fields at both the northern and southern open ocean boundaries in the Atlantic because these are significant sources of low $\mathrm{N}^{*}$ water, and failing to include the low $\mathrm{N}^{*}$ Arctic inflow will tend to underestimate the amount of nitrogen fixation required to maintain the observed $\mathrm{N}^{*}$ conditions (Yamamoto-Kawai et al. 2006). We do not employ a coastal relaxation to observed N:P ratios to incorporate the effects of shelf denitrification. Shelves are not resolved in this coarse resolution model. Although Fennel et al. (2006) find denitrification to be a significant loss term in the North American shelf nitrogen budget, surface $\mathrm{N}: \mathrm{P}$ ratios from historical observations (GLODAP database, Key et al., 2004, not shown) are not significantly depressed near the edge of the coastline, suggesting that the impact of shelf denitrification does not extend offshore.

The physical model is spun up for 25 years before the biogeochemical model is initialized and run. The modeled $\mathrm{N}^{*}$ and nutrient distributions have a rapid initial adjustment, stabilizing after 20 years, though they continue to adjust gradually as the model physics and biogeochemical cycles equilibrate. The simulations presented here are shown after 30 years for the remineralization sensitivity runs (Sect. 3.5), and 60 years for all other simulations. For the latter, the nutrient concentrations in the $\mathrm{N}^{*}$ maximum are changing by less than $0.003 \%$ from year 55 to year 60 of the model simulation.

\subsection{Model runs and tuning procedures}

The main run solution, which we refer to in the following discussion as the NSTAR run, was tuned to reproduce the observed $\mathrm{N}^{*}$ anomaly distribution and magnitude in the Atlantic as well as possible. The in situ data used for comparison with the model are described below. $\mathrm{N}^{*}$ was calculated following GS97:

$\mathrm{N} *=\left(\mathrm{NO}_{3}^{-}-16 \mathrm{PO}_{4}^{-3}+2.9\right) \times 0.87$

with the model-generated $N *$ calculated by setting $\mathrm{NO}_{3}=$ DIN and $\mathrm{PO}_{4}=$ DIP. The model was also tuned to reproduce surface chlorophyll, and both surface and subsurface 

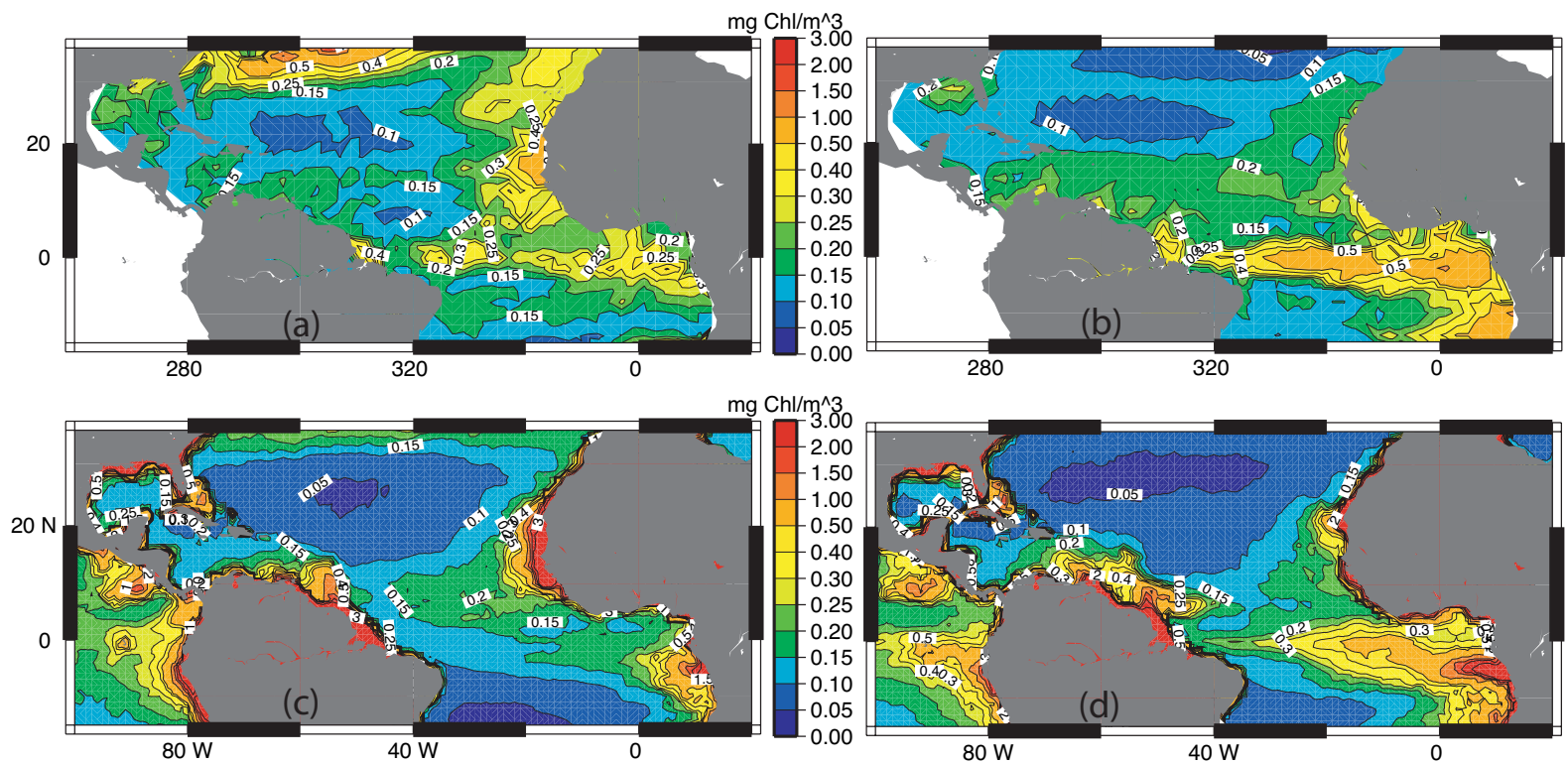

Fig. 2. Surface phytoplankton chlorophyll $\left(\mathrm{mg} \mathrm{Chl}^{\mathrm{m}} \mathrm{m}^{3}\right.$ ) for (a) spring (April) and (b) fall (August) for the NSTAR model run and (c) spring (April) and (d) fall (August) for a climatology based on the SeaWiFS satellite data from 1998 through 2005.

absolute DIN, DIP and DIFe concentrations (see Sect. 3.1). The primary tuning parameters were: the natural mortality rate of the diazotrophs $\left(s_{T}\right)$, which is used to modulate the nitrogen fixation rate; the sinking rate of detritus $\left(w_{s}\right)$, which modulates all nutrient export length scales simultaneously and is used to balance the inputs of nitrogen from nitrogen fixation (following the tuning procedure described in Hood et al., 2004); and the relative remineralization rates of the $D_{N}$, $\mathrm{D}_{\mathrm{P}}$ and $\mathrm{D}_{\mathrm{Fe}}\left(e_{\mathrm{DN}}, e_{\mathrm{DP}}\right.$ and $e_{\mathrm{DFe}}$, respectively), which separately determine the export length scales for $\mathrm{N}, \mathrm{P}$ and $\mathrm{Fe}$ and therefore the relative availability of DIN, DIP and DIFe in the upper ocean and also the distribution of $\mathrm{N}^{*}$ at depth (see Sect. 3.5). It should be noted that these parameters are not independent because diazotroph biomass and nitrogen fixation rate (and also phytoplankton biomass and primary production rate) are also strongly influenced by $w_{s}, e_{\mathrm{DN}}, e_{\mathrm{DP}}$ and $e_{\mathrm{DFe}}$ which determine the surface nutrient concentrations.

\section{Results and discussion}

\subsection{Surface fields}

The primary goals in this study are to reproduce the $\mathrm{N}^{*}$ patterns in the Atlantic (e.g., GS97), assess the sensitivity of the modeled $\mathrm{N}^{*}$ distributions to the relative rates of $\mathrm{D}_{N}$ and $\mathrm{D}_{P}$ remineralization, and quantify the influence of phosphorus and iron limitations on nitrogen fixation rate. However it is important to capture the gross patterns of the seasonal evolution of surface chlorophyll, as well as the surface and subsurface nutrient distributions in order to determine whether or not the biogeochemical cycles in the model are reasonable.
Here we evaluate the model performance relative to climatological surface data.

Figures $2 \mathrm{a}$ and $\mathrm{b}$ show the NSTAR run surface chlorophyll concentration in spring and late summer, to be compared with Figs. $2 \mathrm{c}$ and $\mathrm{d}$ which are climatologies for the same time periods constructed from SeaWiFs satellite ocean color data from 1997-2005. The model generally reproduces the seasonal cycles of upwelling, the North Brazil Current retroflection and the spring bloom to the far north of the domain. The model physics are consistent with other coarse resolution models, with the Gulf Steam hugging the North American shelf too far north of Cape Hatteras. This tends to advect biological quantities to the north rather than to the east in the model domain, and leads to the tongue like spring bloom, rather than the more zonal orientation in the observations. This is not an error that greatly affects the Atlantic tropics however, where the bulk of the nitrogen fixation occurs well south of the northern subtropical gyre boundary.

The model also tends to overestimate equatorial upwelling and underestimate coastal upwelling, as is generally the case for coarse ocean models, leading to excess phytoplankton biomass along the equator and low phytoplankton biomass along the coastlines (see also Hood et al., 2004). The NSTAR run is less oligotrophic in the subtropical gyre than the observations, which may be due to insufficient export in this region. The model also doesn't reproduce the very high chlorophyll concentrations observed in the Amazon plume and North Brazil Current retroflection. This latter discrepancy is, at least to some degree, due to the fact that the satellite climatology overestimates chlorophyll in this area due to the high values of colored dissolved organic matter 


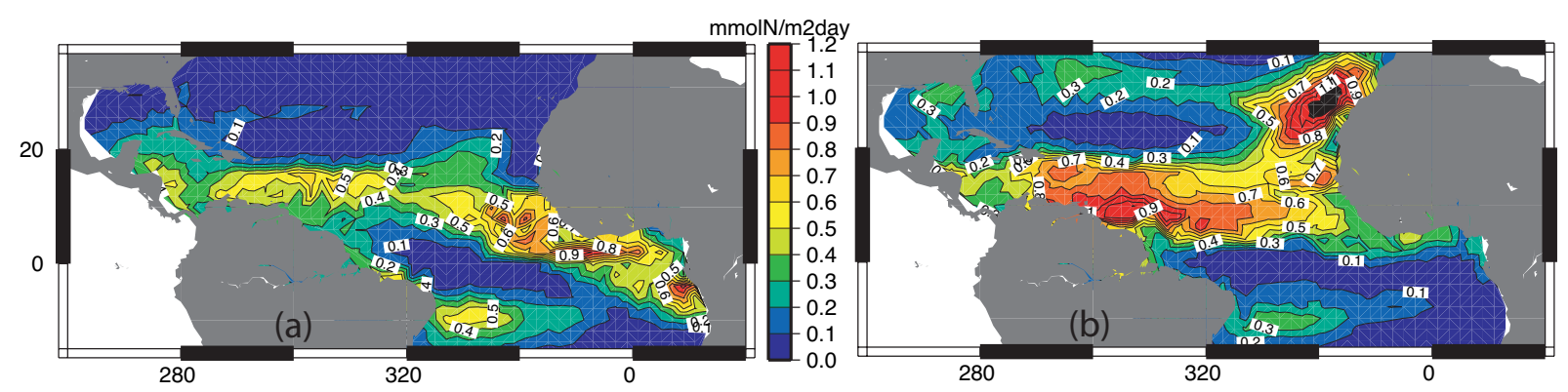

Fig. 3. Surface nitrogen fixation rates for (a) spring (April) and (b) fall (August) are shown for the NSTAR run.
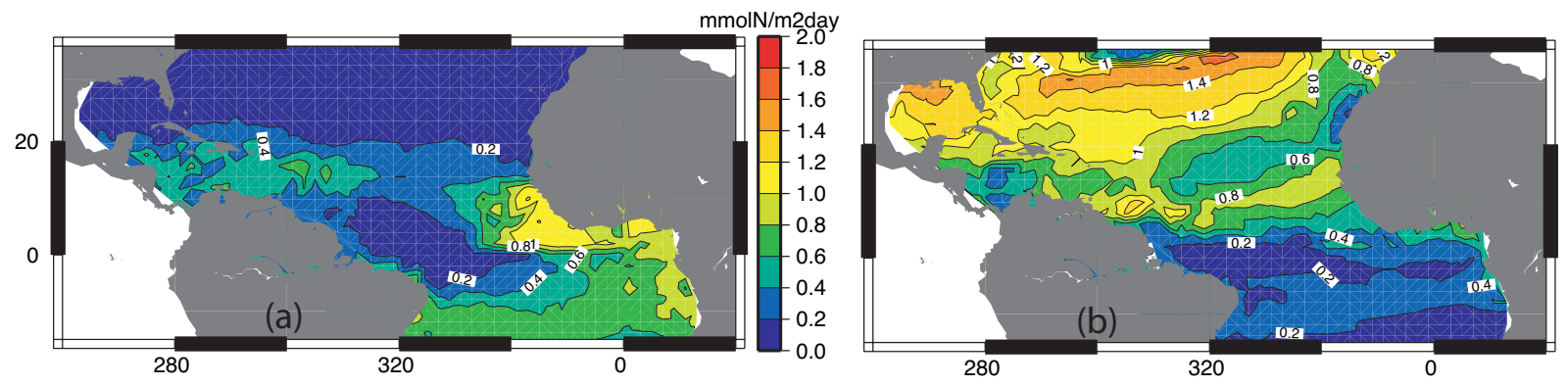

Fig. 4. Surface nitrogen fixation rates for (a) spring (April) and (b) fall (August) are shown for the NOLIM run.

associated with the river plume (Del Vecchio and Subramaniam, 2004).

Modeled $\mathrm{N}_{2}$-fixation rate for the spring and fall seasons in the NSTAR run is shown in Fig. 3. For comparison with our previous model results, see Fig. 7 in Hood et al. (2004). The NSTAR run reproduces many of the same temporal and spatial patterns generated in previous runs that did not include phosphorus or iron limitations, but there are also some substantial differences. Both solutions generate elevated rates off northwest Africa at $\sim 10^{\circ} \mathrm{N}$ and in the Gulf of Guinea with markedly higher rates in spring in the latter. Both solutions also produce elevated rates in two zonal bands situated to the north and south of the equator in spring, and both have much higher rates overall in the North Atlantic in summer. In general, the comparison between the NSTAR run and our previous model results show strong similarities in the $\mathrm{N}_{2}$-fixation rate patterns in tropical waters with, perhaps, somewhat more realistic seasonality in the NSTAR run because the rates do not decrease as much in the winter (Hood et al., 2004) and the rates are also lower in the Gulf of Guinea (Fig. 3).

However, there are some dramatic differences between the NSTAR run and our previous model results in the subtropics. For example, in late summer there is a minimum in the $\mathrm{N}_{2}$-fixation rate in the southern Sargasso and in the Gulf of Mexico in the NSTAR run (Fig. 3b), whereas there are maxima in the rates in these regions in Hood et al. (2004). The rates are reduced in the NSTAR run in these regions due to phosphorus limitation, which suppresses $\mathrm{N}_{2}$-fixation over a broad area of the subtropics that extends from the Gulf of Mexico to $\sim 30^{\circ} \mathrm{W}$ (see discussion below). Another aspect of the NSTAR run that differs significantly from Hood et al. (2004) are the high $\mathrm{N}_{2}$-fixation rates north of $30^{\circ} \mathrm{N}$ in the late summer and Fall (Fig. 3b). Observations show Trichodesmium extending further north off of Africa during summer and fall (Herñandez-León et al., 1999; Tyrrell et al., 2003) as in the NSTAR run. However, Trichodesmium colony concentrations and rates of $\mathrm{N}_{2}$-fixation decline dramatically from south to north approaching Bermuda in the western Atlantic, and it is generally believed that concentrations and rates remain low further north (Carpenter and Romans, 1991; Orcutt et al., 2001). The model however, allows $\mathrm{N}_{2}$-fixation to occur north of Bermuda in the summer and fall (Fig. 3) because this region becomes highly stratified during this time of year and depleted in DIN, i.e., ideal conditions for diazotrophic growth. Because there is a strong meridional temperature gradient in this region, the model predicted $\mathrm{N}_{2}-$ fixation rate can be reduced in this region by the addition of a simple temperature constraint on the diazotroph growth rate (e.g., following Moore et al., 2002a). We did not impose this constraint because there is evidence for elevated rates of $\mathrm{N}_{2}$-fixation in these waters, i.e., spring time whole water incubations show significant rates of nitrogen fixation north of $35^{\circ} \mathrm{N}$ that are comparable to those generated in this region by the model in spring, suggesting that microbial diazotrophs are active in the region (J. Montoya, unpublished 

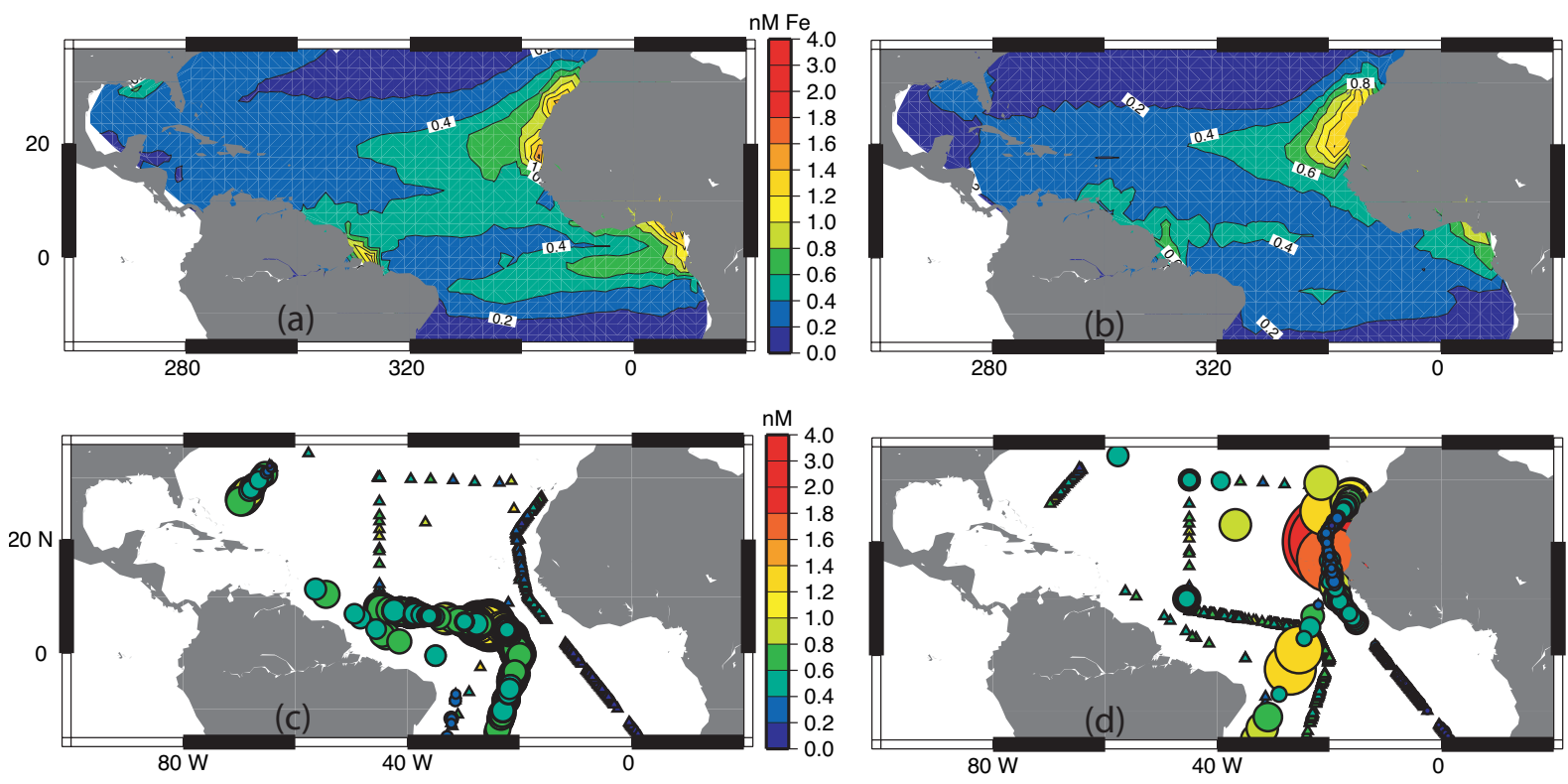

Fig. 5. Surface iron concentrations in $\mathrm{nM}$ for the model NSTAR run for (a) spring (April) and (b) fall (August), and the available observations (Parekh et al., 2005; Bergquist and Boyle, 2006; Bowie et al., 2002) for (c) spring (March, April, May) and (d) fall (July, August September). Because of the paucity of observational data, the surface iron observations are shown in entirety as small triangles, and the seasonal data are indicated as larger circles proportional to concentration.

observations and see also Langlois et al., 2005). For this reason, we have chosen to retain the signal in the NSTAR solution. This area does not contribute significantly to basin wide $\mathrm{N}_{2}$-fixation because of its transient nature and relatively modest rates, i.e., the region from $30^{\circ} \mathrm{N}$ northward, and east of $30^{\circ} \mathrm{W}$ represents only $4 \%$ of the basin total nitrogen fixation rate.

Because the physical model differed between this study and the solutions presented in Hood et al. (2004) and Coles et al. (2004) we repeated the NSTAR run without phosphorus and iron limitation (NOLIM run) in order to determine specifically their influence (Fig. 4). To remove the effect of phosphorus and iron limitation, we set the phosphorus and iron compartments to cycle identically to nitrogen (same initial conditions, source and sink functions, half saturation coefficients, and 1:1:1 nutrient ratios); effectively the phosphorus and iron fields were identical to the nitrogen fields. Since nutrient limitations are not multiplicative but rather the most limiting nutrient reduces the maximum growth rate, this choice removes multiple limiting nutrients without altering the model equations. The NOLIM simulation has a greater basin averaged nitrogen fixation rate $\left(6.5 \times 10^{12} \mathrm{~mol} \mathrm{~N} \mathrm{yr}^{-1}\right)$ than the NSTAR run $\left(3.4 \times 10^{12} \mathrm{~mol} \mathrm{~N} \mathrm{yr}^{-1}\right.$, Table 1$)$ indicating that phosphorus and/or iron limitation does play a significant role in limiting the net basin averaged rate. The primary differences between these runs is that nitrogen fixation in the western North Atlantic extends farther north in fall without $P$ and $\mathrm{Fe}$ limitations (compare Figs. $3 \mathrm{~b}$ and $4 \mathrm{~b}$ ), i.e., generating high rates throughout the subtropical gyre and in the Gulf of Mexico. This also increases chlorophyll concentrations in response to the additional input of new nitrogen without phosphorus limitation of either diazotrophy or primary production (not shown).

It is not possible to determine which of the $\mathrm{N}_{2}$-fixation patterns in the NSTAR and NOLIM simulations is more correct based on the sparse observations (see Fig. 5 in Hood et al., 2004), though the addition of the $\mathrm{P}$ and Fe limitations does appear to depress $\mathrm{N}_{2}$-fixation in the Sargasso Sea and Gulf of Mexico more than it should. On the other hand, some aspects of the NSTAR simulation appear to be more realistic, i.e., less seasonality in the tropics, lowered rates in the Gulf of Guinea and high rates extending further north in the eastern subtropical Atlantic as discussed above. Regardless, adding phosphorus and iron cycling provides several important benefits. The addition of these nutrients allow us to estimate the basin-wide $\mathrm{N}_{2}$-fixation rate using $\mathrm{N}^{*}$ as the constraint, rather than tuning to observed diazotroph biomass as in Coles et al. (2004) and Hood et al. (2004). The latter approach is flawed because of the limited availability of biomass observations and the general lack of data on diazotrophs other than Trichodesmium. We find that tuning our model to $\mathrm{N}^{*}$ gives rates of $\mathrm{N}_{2}$-fixation that are substantially higher than tuning to Trichodesmium biomass and these rates are more consistent with earlier geochemical rate estimates derived from observed $\mathrm{N}^{*}$ using inverse methods (e.g., GS97; see Sect. 3.6 and Table 1 below).

Figures $5 \mathrm{a}$ and $\mathrm{b}$ show the NSTAR model run surface iron concentration for spring and summer, and Figs. $5 \mathrm{c}$ and $\mathrm{d}$ 

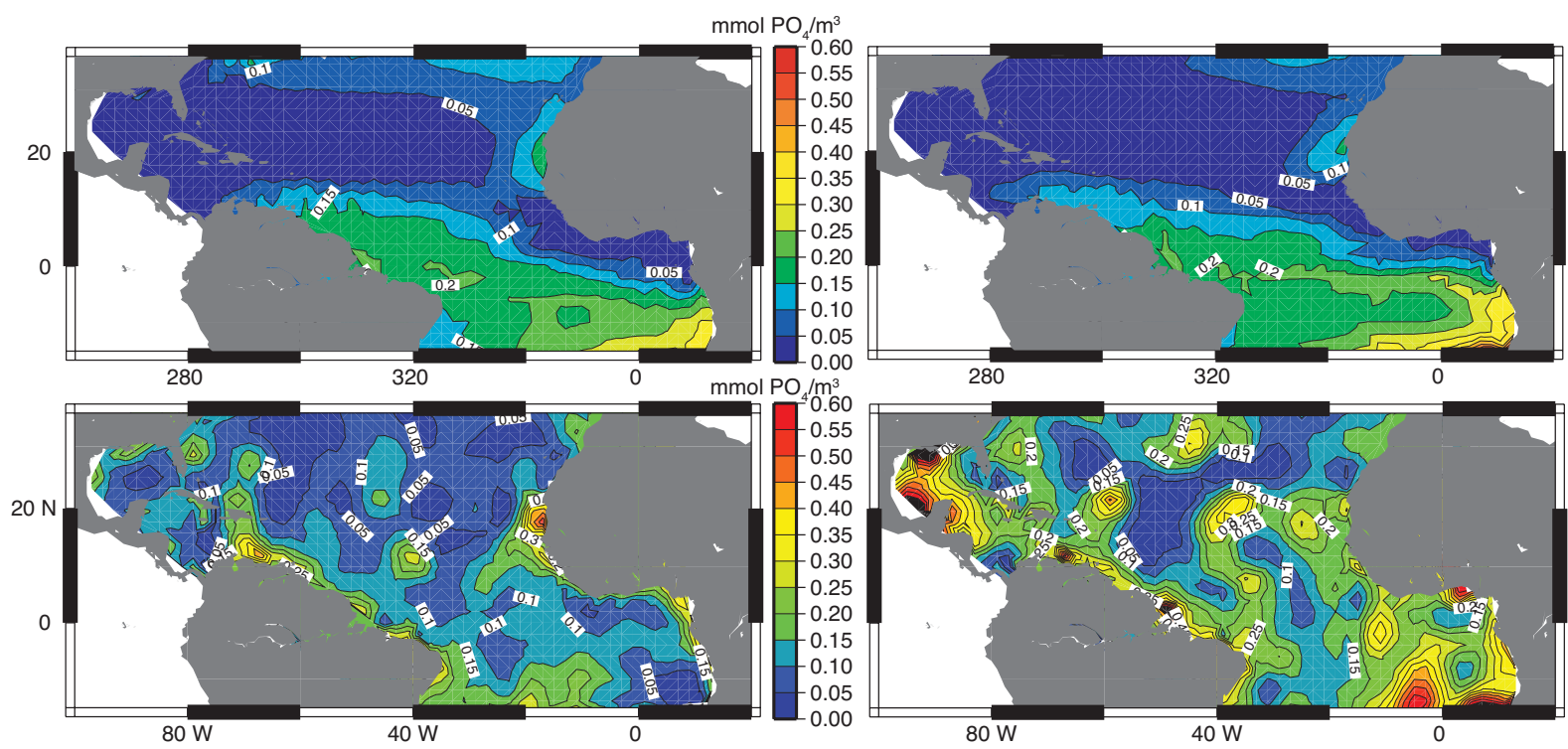

Fig. 6. Surface phosphorus concentrations in $\mathrm{mmol} / \mathrm{m}^{3}$ for the model NSTAR run for (a) spring (April) and (b) fall (August), and a nutrient climatology (Conkright et al, 1994) for (c) spring (April) and (d) fall (August).

show surface concentrations from a compilation of Parekh et al. (2005), with additional observations from Bergquist and Boyle (2006) and Bowie et al. (2002). The observations show all available data in small triangles, with larger circles showing data collected over three month periods in spring (Fig. 5c) and late summer (Fig. 5d). These data indicate that nearsurface Fe concentrations off of the West African coast vary widely, between $\sim 0.2-2.5 \mathrm{nM}$ depending upon the cruise and time of year, with the highest concentrations occurring at about $20^{\circ} \mathrm{N}$. The model surface fields show maxima in the same general area with surface concentrations varying from $\sim 0.10 \mathrm{nM}$ at the northern and southern limits of the domain to $>1.0 \mathrm{nM}$ off the coast of West Africa. These concentrations are consistent with the patterns in the modeled dust deposition fields (Luo et al., 2003; Mahowald et al., 2003) and the higher reported in situ surface concentrations (Bowie et al., 2002; C. Measures and W. Landing, unpublished data; and see also Anderson and Henderson, 2005).

To the west, the model surface concentrations are lower and broadly consistent with the observed values, near $0.2 \mathrm{nM}$ with higher values along the equator, and diminishing to north and south. There is a suggestion in the data from $35^{\circ} \mathrm{N}$, $75^{\circ} \mathrm{W}$ of decreasing surface iron concentrations from spring to summer, which is consistent with the patterns in the model, however the data density is insufficient to constrain the model beyond giving a reasonable range of concentrations. Dissolved iron from the October- November SOLAS M55 cruise also support this pattern of higher surface iron concentrations to the east along $10^{\circ} \mathrm{N}$ (Voss et al., 2004; Croot et al., 2004). The model has lower surface iron concentrations in the northern Gulf of Mexico and in the northwestern Atlantic in general in the fall (Fig. 5b). This arises because the dominant supply of iron to these regions comes from enhanced vertical mixing in wintertime, coupled with maximum springtime dust deposition. Deposition is lowest north of $30^{\circ} \mathrm{N}$ during fall and winter, so the low model concentrations there are consistent with the deposition fields.

Figure 6 shows surface phosphate concentrations in spring and fall for the NSTAR model runs compared to the World Ocean Atlas 1994 climatology (Conkright et al, 1994). This comparison suggests that the model slightly underestimates spring and fall surface phosphorus concentrations (by less than $0.1 \mathrm{mmol} \mathrm{m}^{-3}$ ). However, the climatology shows higher surface phosphorus concentrations than vertical sections through the area (shown below), suggesting that the historical database may be somewhat high, perhaps due to averaging and smoothing, relative to more recent instantaneous measurements. Similar discrepancies are observed in fall (Figs. $6 \mathrm{~b}$ and d). In general, the model and data suggest that the Gulf of Mexico and central Sargasso Sea have vanishingly low concentrations (see below and also $\mathrm{Wu}$ et al., 2000 for phosphate observations from the Sargasso Sea). In spring, these low levels extend over to the southwestern African coast and into the northern Gulf of Guinea. Fall patterns are similar but with higher values in the Gulf of Mexico and Gulf of Guinea in the historical dataset. In both seasons, higher levels associated with the North Brazil Current are evident in the model and observations. Equatorial and southern hemisphere concentrations in the model and observations are also higher than subtropical phosphate levels as a result of upwelling, and wintertime mixing. 


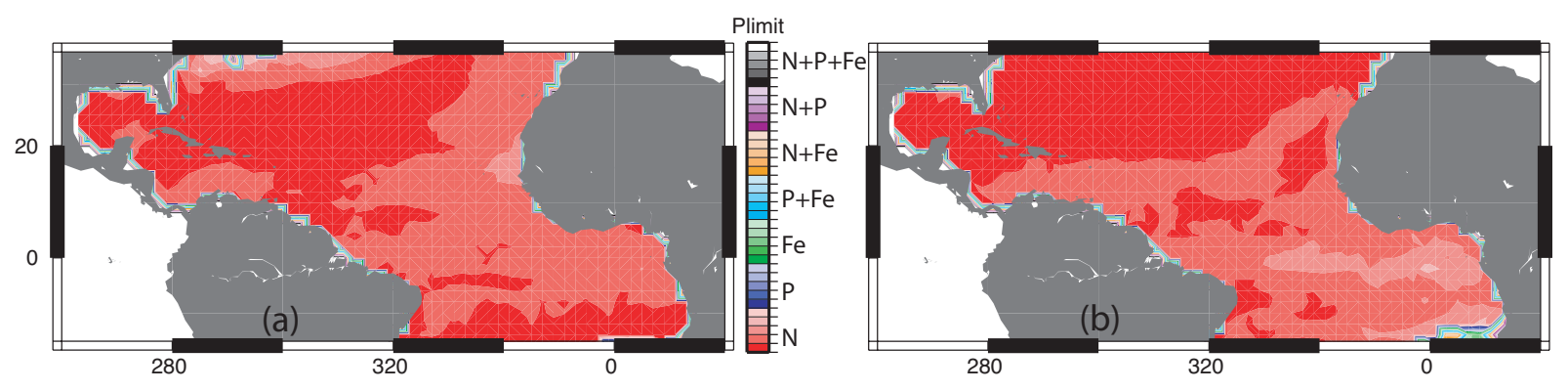

Fig. 7. Phytoplankton growth limitations for the NSTAR model run for (a) spring (April) and (b) fall (August). Each color indicates a different limiting nutrient, and the intensity of the shade reflects the intensity of the limitation, from low limitations (nearly white) to severe limitation (intense color). Co-limitation of the nutrients is indicated where the degree of limitation is within $15 \%$ for more than one nutrient, and is indicated by a shade of color.
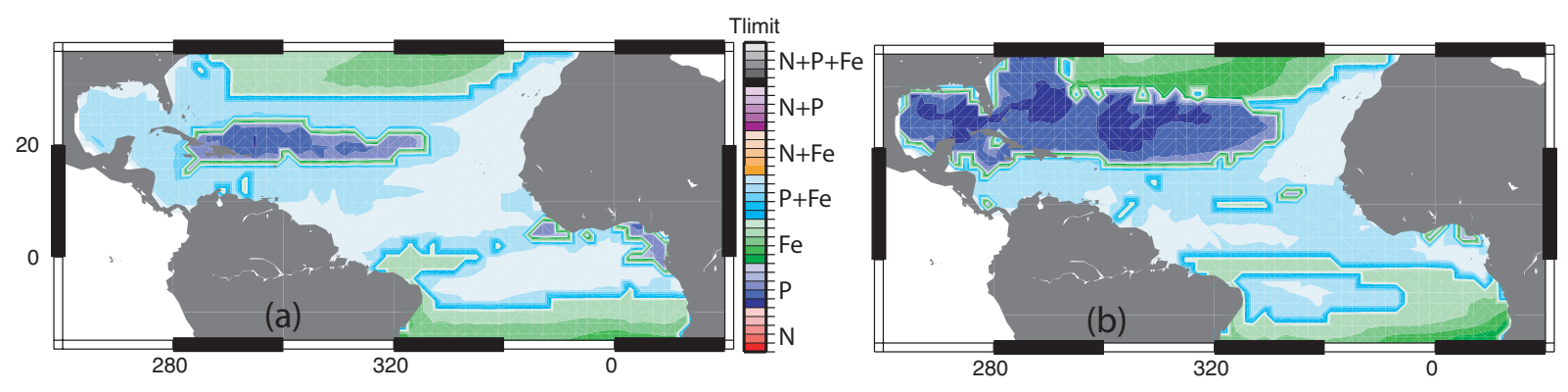

Fig. 8. Diazotroph growth limitation for the NSTAR model run for (a) spring (April) and (b) fall (August). Each color indicates a different limiting nutrient, and the intensity of the shade reflects the intensity of the limitation, from low limitations (nearly white) to severe limitation (intense color). Co-limitation of the nutrients is indicated where the degree of limitation is within $15 \%$ for more than one nutrient, and is indicated by a shade of color.

\subsection{Nutrient limitation patterns}

Recent observational work (Mills et al., 2004; Moore et al., 2006) has clarified the role of various macro and micronutrient limitations in modulating phytoplankton, diazotroph, and bacterial growth rates in the Atlantic Ocean. The Mills et al. (2004) study shows the general dominance of nitrogen in limiting phytoplankton growth in the tropical Atlantic $\left(4^{\circ} \mathrm{N}-11^{\circ} \mathrm{N}, 35^{\circ} \mathrm{W}-18^{\circ} \mathrm{W}\right)$, while iron and phosphorus are observed to co-limit diazotrophy in the same region. In contrast, in a complimentary study Moore et al. (2006) demonstrate iron limitation of primary productivity during the spring bloom in the central (temperate) North Atlantic. These studies allow us to identify whether the model is reproducing the appropriate elemental (nitrogen vs. phosphorus vs. iron) limitations on growth rates. Figures 7 and 8 show the greatest limitation on phytoplankton and diazotroph growth respectively in the spring and fall seasons. These limitations are calculated following equations $\mathrm{A} 2$ and $\mathrm{A} 4$, as a function of dissolved inorganic nutrient concentration and the half saturation constant for each phytoplankter. The magnitude of the limitation ( 0 to 1 ) reflects the factor that multiplies the maximum growth rate, thus darker shades indicate more severe nutrient limitation and slower growth rate, while the color indicates the limiting nutrient. Where two (or three) limitations are within $15 \%$ of each other, it is assumed that they are co-limiting, and they are indicated with a different shade, though in the model equations only the most limiting nutrient is used to restrict growth.

Figures $7 \mathrm{a}$ and $\mathrm{b}$ show phytoplankton growth limited by nitrogen in the Atlantic in the model in both spring and late summer. Nitrogen is less limiting in upwelling zones, such as the equator and coastal North Africa. In the west, off South America, where nitrogen fixation rates are high, nitrogen is also slightly less limiting. Phytoplankton growth rate is substantially reduced (to .2 of the maximum) in the northern part of the domain in the subtropical gyre.

Figure 8 shows the corresponding limitation maps for spring and summer diazotroph growth, and hence $\mathrm{N}_{2}$-fixation rate. By definition, nitrogen never limits diazotroph growth. The model predicts modest co-limitation of $\mathrm{N}_{2}$-fixation by both iron and phosphorus over most of the tropics $\left(20^{\circ} \mathrm{N}\right.$ to $10^{\circ} \mathrm{S}$ ), with stronger limitations in the western North Atlantic. Phosphorus becomes a stronger limiting factor in the southern Sargasso Sea and Gulf of Mexico, particularly in fall. This is consistent with measurements from the Bermuda 

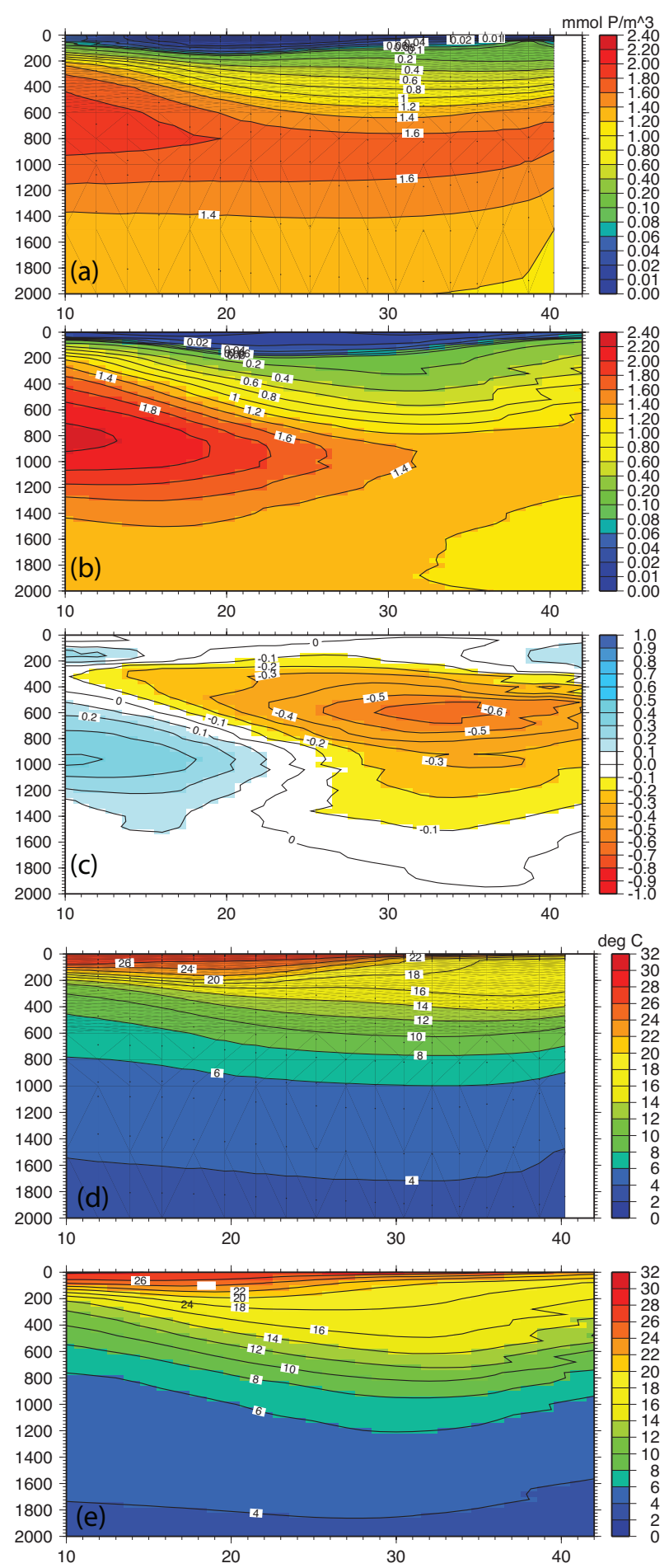

Fig. 9. Vertical sections of phosphate at $52^{\circ} \mathrm{W}$ in July for (a) the NSTAR model run, and (b) for the WOCE A20 section at $52^{\circ} \mathrm{W}$, (c) the model phosphate subtracted from observations, d) NSTAR model run potential temperature, e) WOCE A20 section potential temperature.
Atlantic Time Series (BATS) station and vicinity that reveal extremely low phosphorus concentrations in surface waters in the Sargasso Sea (Wu et al., 2000; Ammerman et al., 2003), suggesting strong potential for phosphorus limitation. Similarly low surface phosphorus concentrations are observed in the central Gulf of Mexico (J. O'Neil, personal communication). Iron limitation becomes increasingly severe to the northeast, where dust deposition rates diminish, and there is no advective supply. Thus, the model reproduces a co-limitation of diazotroph growth rate by phosphorus and iron in the tropics as observed by Mills et al. (2004), though the magnitude of the limitation may be somewhat lower than the observations suggest. This may in part be due to other factors that limit growth, such as light which are included in the model and reduce the uptake of surface nutrients but are not considered in the experimental design of Mills et al. (2004). The model also reproduces iron limitation of primary productivity during the spring bloom in the central (temperate) North Atlantic as demonstrated by Moore et al. (2006) (not shown). It is perhaps unsurprising that the limitations are reasonable because the model generates surface concentrations of nitrogen, iron and phosphorus (Figs. 5 and 6) that are close to observations, and the model limitations are based on the ambient concentrations relative to half-saturation constants specified from measurements off the west coast of Africa (see Appendix A1).

\subsection{Subsurface fields}

The surface ocean ecosystem and chemical fields adjust rapidly in the model to the seasonal and interannual variability in atmospheric forcing and iron deposition flux fields. However, the conditions at depth spin up over much longer time scales. Here we use selected vertical sections to show the model nutrient fields at depth and to validate the remineralization length scales chosen for nitrogen, phosphorus, and iron. It should be noted, however, that Bates and Hansell (2004) have shown that there is significant temporal variability in $\mathrm{N}^{*}$ at BATS, with excess nitrogen values varying by as much as a factor of 3 during different time periods, perhaps associated with the phase of the North Atlantic Oscillation (see also Hood et al., 2001). The WOCE A20 line (July, 1997) shown here (Fig. 9c) was evaluated by Bates and Hansell (2004), and shown to have lower excess nitrogen than a more recent (May 2001) section along the same meridian. Thus, the comparison of these observations with the climatological model is necessarily qualitative.

Figure 9 shows a comparison of phosphate concentrations for the NSTAR run and a WOCE meridional section along $52^{\circ} \mathrm{W}$ (A20, July 1997). The section (Fig. 9) cuts through the Sargasso Sea, and regions with high observed and simulated nitrogen fixation rates. Surface phosphate is below $0.025 \mathrm{mmol} \mathrm{m}^{-3}$ everywhere in the observations. The model has similarly low surface concentrations. A subsurface maximum $\left(>2.2 \mathrm{mmol} \mathrm{m}^{-3}\right)$ with southern hemisphere origins is 
centered at $800 \mathrm{~m}$ in the observations, and also in the model, though the model maximum is weaker $\left(>1.8 \mathrm{mmol} \mathrm{m}^{-3}\right)$. This maximum also is maintained farther to the north in the model, which will tend to cause the model to underestimate $\mathrm{N}: \mathrm{P}$ ratios and $\mathrm{N}^{*}$. Figure $9 \mathrm{c}$ shows the two sections differenced, with positive values reflecting higher observed phosphorus concentrations. Although the surface and deep concentrations match very well, the region at $600 \mathrm{~m}$ near 30 $35^{\circ} \mathrm{N}$ shows significantly higher modeled concentrations. This is largely due to errors in the model physics. To show these errors, we include two vertical temperature sections (Figs. 9d, e). The model does not have good vertical resolution in the area of mode water formation $\left(35-40^{\circ} \mathrm{N} 0-400 \mathrm{~m}\right.$ in the model) and the thermocline and phosphocline are correspondingly diffuse. The errors in the modeled phosphorus clearly correspond to areas where the model does not represent the thermocline well, suggesting that the phosphorus distribution would improve with higher vertical resolution. The phosphocline is shallow $(100 \mathrm{~m})$ at the southern edge of the section in both model and observations, it deepens to nearly $600 \mathrm{~m}$ at $30^{\circ} \mathrm{N}$ in the observations following the thermocline with a secondary seasonal nutricline higher in the water column. The model phosphocline is generally shallower, which may reflect an absence of deep mixing in the northern gyre in winter.

In general, the good comparison between the modeled and observed subsurface phosphorus distributions suggests that the remineralization length scale for phosphorus in the model (122 m with a nominal sinking rate of $55 \mathrm{~m} / \mathrm{d}$, see Appendix B) is approximately correct. Further sensitivity tests of the importance of this length scale are discussed below in Sect. 3.5.

A vertical section of dissolved inorganic iron concentration along $28^{\circ} \mathrm{W}$ for the NSTAR run is shown in Fig. 10a. This section is chosen for comparison with a vertical section of dissolved Fe along WOCE line A16N sampled from May to August, 2003 (not shown, Measures and Landing, unpublished data; see Fig. 1 in Anderson and Henderson, 2005) it is also compared with the deep profiles from Bergquist and Boyle (2006) (Fig. 10b). The Measures and Landing section shows a very shallow ferrocline at $150-200 \mathrm{~m}$ between the equator and $20^{\circ} \mathrm{N}$ marking the transition from surface concentrations of $\sim 1 \mathrm{nM}$ to $>2 \mathrm{nM}$ below. This feature is also observed in the profile at $10^{\circ} \mathrm{N}, 45^{\circ} \mathrm{W}$ from Bergquist and Boyle (2006) (Fig. 10b), although their subsurface maximum is only half the Measures and Landing observations. Bergquist and Boyle attribute the feature to remineralization of organic matter in the low oxygen zone of the eastern Atlantic slowly ventilated shadow zone. The model reproduces this feature as long as iron is input from the atmosphere as detrital iron $\left(\mathrm{D}_{\mathrm{Fe}}\right)$ that must remineralize prior to becoming bioavailable (Fig. 10a). If iron flux at the surface enters the model dissolved iron pool directly, the surface concentrations cannot be taken up quickly enough to show a surface minimum and subsurface maximum. Nonetheless, the model

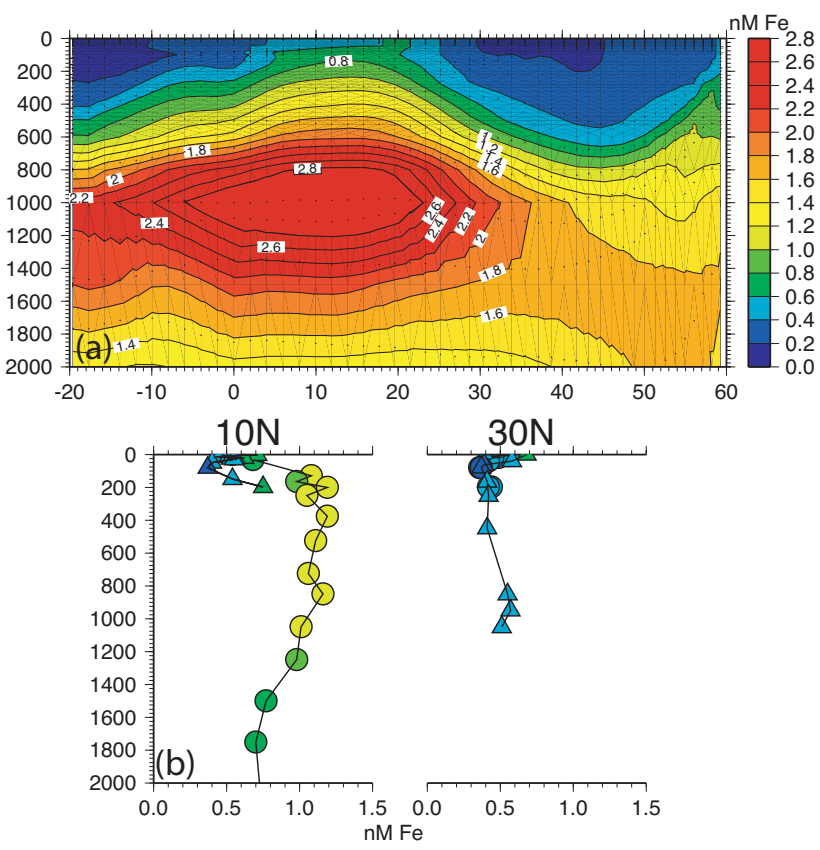

Fig. 10. (a) Vertical section of dissolved inorganic iron $\mathrm{nM}$ for the NSTAR model along $28^{\circ} \mathrm{W}$. (b) two deep profiles from Bergquist and Boyle 2005 at $10^{\circ} \mathrm{N}, 45^{\circ} \mathrm{W}$, and $30^{\circ} \mathrm{N}, 45^{\circ} \mathrm{W}$.

ferrocline between $0-20^{\circ} \mathrm{N}$ is still more diffuse than the observations. The subsurface Fe concentration maximum in the model is comparable to the Measures and Landing data $(\sim 1.5$ to $>2 \mathrm{nM} \mathrm{Fe}$ ), but higher than the maximum in the Bergquist and Boyle (2006) $10^{\circ} \mathrm{N}$ profile ( $1-1.3 \mathrm{nM}$, Fig. 10b). The latter are from a profile located farther to the west, where presumably iron deposition rates are lower. The subsurface maximum between $0-20^{\circ} \mathrm{N}$ in the model is also somewhat deeper (centered at $\sim 1000 \mathrm{~m}$ ) than observed. In the model, this high Fe feature is primarily a result of surface dust deposition, which is co-located with the highly productive coastal and open ocean (Guinea Dome) upwelling region off western Africa. The high production rate results in higher sinking rates and greater Fe export.

At $30^{\circ} \mathrm{N}$ the model profile compares well with the Landing and Measures section, showing maximum Fe concentrations below $600 \mathrm{~m}$, and roughly comparable concentrations $(\sim 1.2-1.8 \mathrm{nM})$. However, these concentrations are substantially higher at depth than reported by Bergquist and Boyle (2006) at $30^{\circ} \mathrm{N}(\sim 0.6 \mathrm{nM}$, Fig. 10b). Spatial heterogeneity in the deep iron distributions (below $1000 \mathrm{~m}$ ) is suggested in the observations, and in the model to a lesser extent; more data are needed to resolve the robustness of these features.

\section{$3.4 \quad \mathrm{~N}^{*}$ comparisons}

Given the limited information on the spatial and temporal distribution of nitrogen fixation rate and biomass of diazotrophic organisms, the anomaly in the nitrogen to 

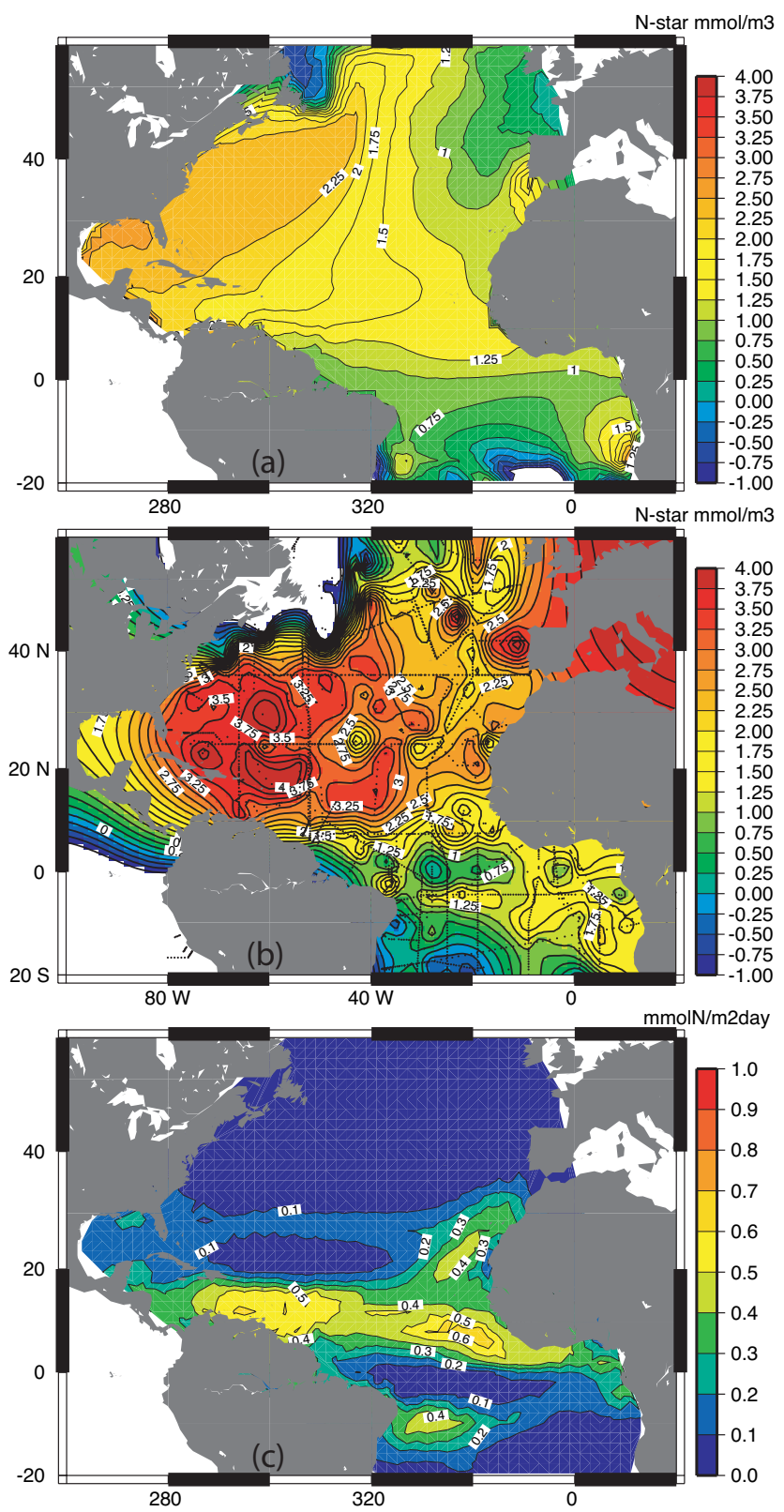

Fig. 11. Isopycnal maps of $\mathrm{N}^{*}$ from (a) the annually averaged NSTAR run at $26.8 \sigma_{\theta}$, (b) the GLODAP bottle database on $26.5 \sigma_{\theta}$, (c) annual average nitrogen fixation rate integrated over the euphotic zone in the NSTAR run.

phosphorus ratio at depth provides, arguably, the most robust means of evaluating the correctness of the model's nitrogen fixation rate. The major caveat is that in order to make a meaningful comparison to the observed $\mathrm{N}^{*}$, the model must form the anomaly in the right place and deposit it over a similar depth range as observed. Achieving this is a significant challenge because it requires 1) modeling the temporal and spatial variability and the magnitude of the surface $\mathrm{N}_{2}$ fixation rate, 2) exporting the $\mathrm{N}: \mathrm{P}$ ratio anomaly that is cre- ated by $\mathrm{N}_{2}$-fixation with the correct remineralization length scale which varies in space and time and, 3) advecting and diffusing this anomaly correctly with the physical model so it ends up in the right place. Here, we calculate $\mathrm{N}^{*}$ (according to Eq. (1) above) on the $26.5 \sigma_{\theta}$ density surface in the NSTAR run (Fig. 11a), and compare it to $\mathrm{N}^{*}$ computed from the GLODAP bottle database (Key et al., 2004) (Fig. 11b). For comparison, the annually averaged nitrogen fixation rate is shown in Fig. 11c. We choose this isopycnal surface in order to compare the model fields and the updated observations with the fields presented in GS97.

The model shows a similar pattern to the observations on this density surface, with maximum $\mathrm{N}^{*}$ concentrated in the subtropical gyre, and extending northward into the eastern subpolar gyre. However, the model $\mathrm{N}^{*}$ maximum is somewhat low, and extends too far up the coast of North America following the misplaced path of the Gulf Stream. The $N^{*}$ pattern also spreads eastward along $15^{\circ} \mathrm{N}$ in both the observations and the model, though more weakly in the latter. A tongue of low $\mathrm{N}^{*}$ water entering the model from the northeast stems from the model boundary conditions which specify low $\mathrm{N}: \mathrm{P}$ ratios at depth in this region, but this feature is not represented in the GLODAP database. Nonetheless, it is clear from comparisons with Fig. 11c that the surface nitrogen fixation rate pattern in the model bears little resemblance to the pattern of $\mathrm{N}^{*}$ at depth. The highest $\mathrm{N}_{2}$-fixation rates should be spatially related to the $\mathrm{N}^{*}$ distribution if particulate export is remineralized at depth in the same region where the nitrogen fixation occurred. Instead, the highest rates of $\mathrm{N}_{2}$-fixation occur in the model, on average, just north of the equator off the coast of Africa, centered on $20^{\circ} \mathrm{W}$, and also in the Caribbean and off the north coast of South America centered at $15^{\circ} \mathrm{N}, 55^{\circ} \mathrm{W}$ (Fig. 11c). These are regions of relatively low and very homogeneous $\mathrm{N}^{*}$ on the $26.5 \sigma_{\theta}$ density surface (Fig. 11a), suggesting that advection of both the fixed nitrogen at the surface, and the exported particulate nitrogen and phosphorus have a strong influence on the $\mathrm{N}^{*}$ distribution pattern. The export from the euphotic zone is concentrated in regions of tropical and equatorial upwelling, except for a local maximum collocated with the Caribbean nitrogen fixation maximum (not shown). The particles that give rise to the $\mathrm{N}^{*}$ signal must then advect horizontally over large distances and ultimately accumulate in the western tropical and subtropical north Atlantic. This conclusion is consistent with the results of Siegel and Deuser (1997) who showed that export trajectories of individual sinking particles have a very strong horizontal component, and also with our unpublished analyses of previous model results which show that export flux at depth usually bears little resemblance to surface productivity patterns.

One of the features of the model-generated $\mathrm{N}_{2}$-fixation pattern that has not been verified by observations is the elevated rates in the Gulf of Guinea and off coastal Africa, as discussed in Hood et al. (2004). While Trichodesmium has been observed anecdotally in these regions, the magnitude of 
the signal in the model is comparable to the more well-known western tropical North Atlantic signal. One argument against significant $\mathrm{N}_{2}$-fixation in these regions is the subsurface $\mathrm{N}^{*}$ signal reported in GS97(see their Figs. 3a, b). Their maps, as well as their mixing analysis comparing $\mathrm{N}^{*}$ to salinity, suggests that any modest increases in nitrogen fixation south of $15^{\circ} \mathrm{N}$ were associated with mixing of high and low $\mathrm{N}^{*}$ watermasses, and not high rates of $\mathrm{N}_{2}$-fixation. The updated observations (Fig. 11b) show local maxima in $\mathrm{N}^{*}$ associated with the Congo Plume, as well as in the eastern Gulf of Guinea, and well south of $15^{\circ} \mathrm{N}$. The model is consistent with these patterns, and it shows that high nitrogen fixation rates in the eastern Atlantic are not inconsistent with the $\mathrm{N}^{*}$ pattern at depth.

$\mathrm{N}^{*}$ signals on isopycnal and depth surfaces are not straightforward to interpret. A significant fraction of the $\mathrm{N}^{*}$ anomaly can be explained by passive advection and mixing on isopycnal surfaces, as the regions of sources and sinks for $\mathrm{N}^{*}$ are relatively localized. However, one must also consider that in the tropical Atlantic the $26.5 \sigma_{\theta}$ isopycnal surface varies in depth from $400 \mathrm{~m}$ in the central subtropical gyre to nearly $100 \mathrm{~m}$ at the eastern boundary and in the equatorial zone. The source of $\mathrm{N}^{*}$ comes from the export of nitrogen rich organic matter from the upper ocean and this remineralization process is a function of depth primarily (Martin et al. 1987), not density. This can be seen in zonal sections of $\mathrm{N}^{*}$ (not shown) which exhibit $\mathrm{N}^{*}$ maxima at about $500 \mathrm{~m}$ across the basin, and if anything deepen to the east. As a result, the model and data both show organic matter remineralization occurring on different density surfaces in both zonal and meridional directions, with high $\mathrm{N}^{*}$ in the western Atlantic preferentially accumulating on shallower surfaces (e.g., $26.75 \sigma_{\theta}$ ), and the eastern Atlantic signal preferentially accumulating on deeper density surfaces (e.g., $27.25 \sigma_{\theta}$ ). Because of these differences, analysis of $\mathrm{N}^{*}$ maps drawn on isopycnal surfaces tend to give the false impression that most of the $\mathrm{N}_{2}$-fixation in the North Atlantic occurs in the west. This is consistent with the analysis of Hansell et al. (2004), who also noted the difference in density at which $\mathrm{N}^{*}$ patterns emerge.

According to this argument the eastern Atlantic nitrogen fixation signal should appear to be more important on deeper isopycnal surfaces due to the zonal uplift of the isopycnals in the east. This is confirmed in Fig. 12, which shows a comparison between the NSTAR run (Fig. 12a) and the observational data (Fig. 12b) on the $27.03 \sigma_{\theta}$ surface. Indeed, neither the model nor the observations show a western intensified $\mathrm{N}^{*}$ pattern on this density surface. Note also that an additional discrepancy between the modeled and observed $\mathrm{N}^{*}$ patterns is revealed on this density surface, i.e., the NSTAR simulation shows high $\mathrm{N}^{*}$ values spreading into the Gulf of Guinea (not shown), rather than a front at $5-10^{\circ} \mathrm{N}$ as in the observations. This occurs because of errors in the circulation pattern of this coarse resolution model. The salinity field on this surface shows high salinity water extending from the central
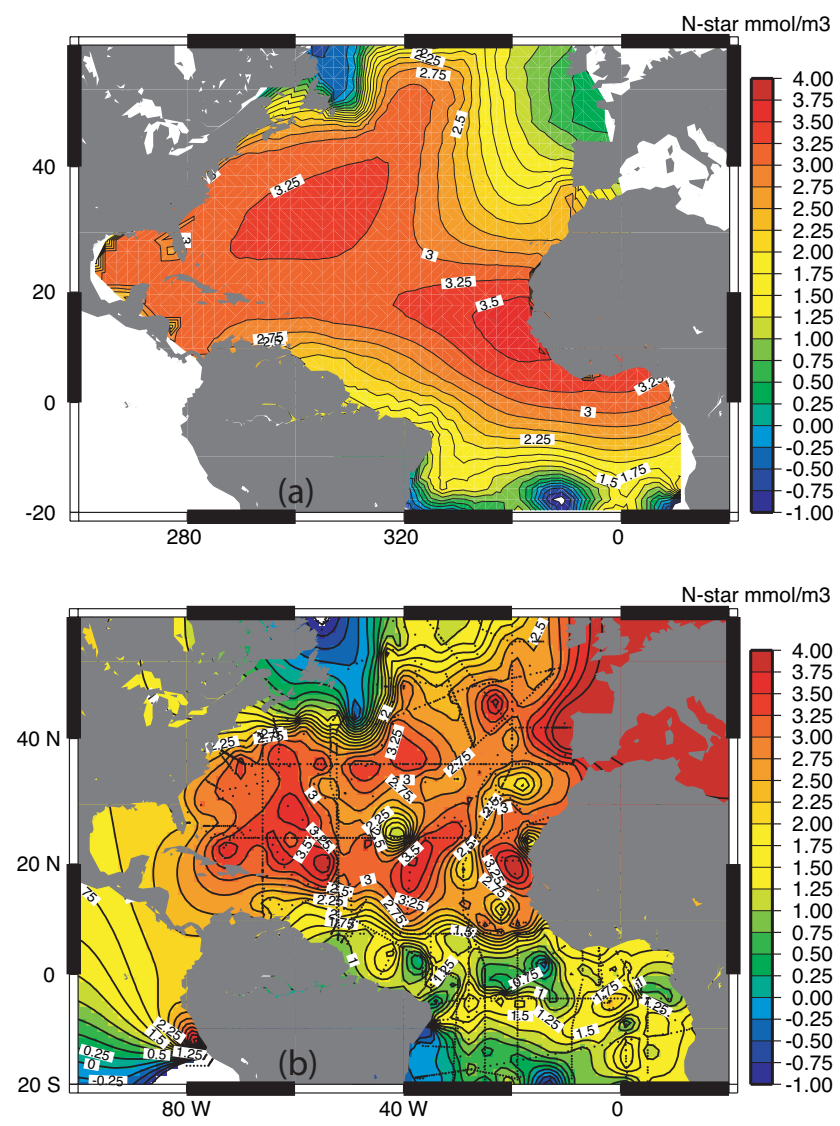

Fig. 12. Isopycnal maps of $\mathrm{N}^{*}$ from (a) the annually averaged NSTAR run at $27.03 \sigma_{\theta}$, (b) the GLODAP bottle database on $27.03 \sigma_{\theta}$.

North Atlantic into the Gulf of Guinea, rather than a welldeveloped salinity front across $5-10^{\circ} \mathrm{N}$ as observed, and the same effect occurs in the $\mathrm{N}^{*}$ distribution. Regardless, it is clearly incorrect to interpret $\mathrm{N}^{*}$ maps as being indicative of patterns of $\mathrm{N}_{2}$-fixation sources because the signals accumulate far from their origins and in regions dictated by the circulation. This problem is compounded by the fact that $\mathrm{N}^{*}$ maps drawn on the $26.5 \sigma_{\theta}$ isopycnal surface tend miss the anomaly on the eastern side of the basin.

The $\mathrm{N}^{*}$ anomaly plotted on vertical sections better illustrates the spatial and depth signatures of the remineralization signal. Figures $13 \mathrm{a}$ and $\mathrm{b}$ show vertical sections of $\mathrm{N}^{*}$ along $52^{\circ} \mathrm{W}$ in July from the NSTAR run compared with observations (WOCE line A20), completed in summertime. The magnitude of the $\mathrm{N}^{*}$ anomaly in the model is approximately correct $\left(\sim 3.5-4.0 \mathrm{mmolN} \mathrm{m}^{-3}\right)$ but the maximum is somewhat deep $(600 \mathrm{~m}-800 \mathrm{~m})$ compared to the observations $(400 \mathrm{~m}-800 \mathrm{~m})$. This suggests that either the sinking rate of detritus is a bit too fast, or that the remineralization of detritus is too slow in this region of the North Atlantic. The model also fails to represent the low $\mathrm{N}^{*}$ signal in the southern end of the transect below $600 \mathrm{~m}$ in the observations. This 

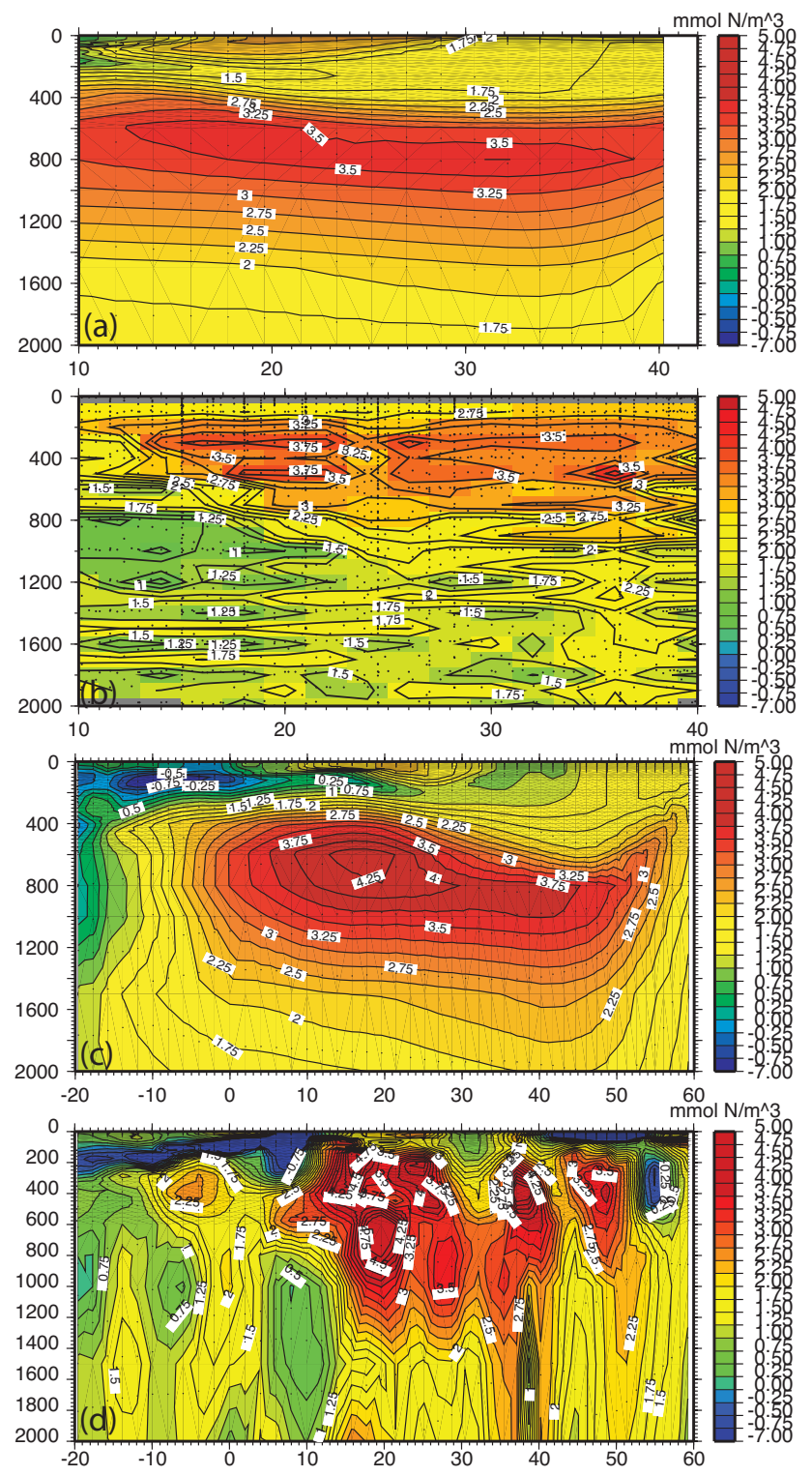

Fig. 13. (a) Vertical section of $N^{*}$ for the NSTAR model along $52^{\circ} \mathrm{W}$, (b) $\mathrm{N}^{*}$ from WOCE A20 at $52^{\circ} \mathrm{W}$, (c) NSTAR model run along $28^{\circ} \mathrm{W}$, (d) $\mathrm{N}^{*}$ from WOA initial conditions at $28^{\circ} \mathrm{W}$.

feature may be due to shelf/slope denitrification, which is not represented in the model. The model does not have high $\mathrm{N}^{*}$ values in the upper ocean at the southern boundary of the section, along the coast of South America in the North Brazil Current retroflection region either. This suggests that the $\mathrm{N}^{*}$ is underestimated in the inflow from the southern hemisphere in the model, which could be due to boundary condition errors or underestimation of nitrogen fixation.

To the east, along $28^{\circ} \mathrm{W}$, we compare the modeled $\mathrm{N}^{*}$ in January (Fig. 13c) with the WOA initial conditions (Fig. 13d). Both sections show a near surface $\mathrm{N}^{*}$ minimum centered at $200 \mathrm{~m}$ between $20^{\circ} \mathrm{S}$ and $20^{\circ} \mathrm{N}$, with its source

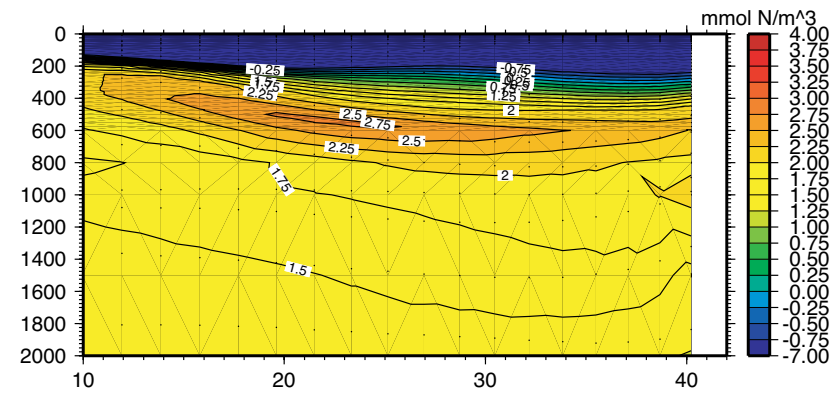

Fig. 14. Vertical section of $\mathrm{N}^{*}$ for the NOFIX model along $52^{\circ} \mathrm{W}$.

from the southern hemisphere. The model and observations both show an $\mathrm{N}^{*}$ maximum between 200 and $1500 \mathrm{~m}$, however the model maximum extends farther south than the observations. The latter is the result of the coarse resolution thermocline tropical - subtropical interactions which manifest themselves in the salinity field as discussed above. The most intense $\mathrm{N}^{*}$ signal is centered at $20^{\circ} \mathrm{N}$ in both the model and observations. The WOA nutrient climatology is noisier than the model, as might be expected. However, to first order the model does represent the basin wide $\mathrm{N}^{*}$ patterns.

One important caveat in these simulations is the possibility that differential remineralization of nitrogen and phosphorus can itself give rise to the $\mathrm{N}^{*}$ signal observed in the model. That is, differential remineralization can generate local positive and negative $\mathrm{N}^{*}$ anomalies in the absence of inputs of new nitrogen from $\mathrm{N}_{2}$-fixation or removal of nitrogen by denitrification simply by remineralizing $\mathrm{N}$ and $\mathrm{P}$ at different places in the water column. However, differential remineralization obviously cannot generate a net positive or negative anomaly over the entire basin all by itself. To explore these effects we carried out a simulation where $\mathrm{N}_{2}$-fixation is eliminated in the model (referred to hereafter as the NOFIX run), though the relaxation to nutrient climatologies at the northern and southern boundaries, and Straits of Gibraltar are maintained. Figure 14 shows the NOFIX N* pattern on the $52^{\circ} \mathrm{W}$ section. The differential remineralization generates a strong negative $\mathrm{N}^{*}$ anomaly in the upper $\sim 200 \mathrm{~m}$ of the water column due to the more rapid remineralization of phosphorus. This negative anomaly is not apparent in the observations (Fig. 13b). The differential remineralization also generates a weak positive anomaly that is distributed over the entire water column below $200 \mathrm{~m}$ with a maximum centered at $\sim 500 \mathrm{~m}$. Thus, the differential remineralization alone can create positive and negative anomalies, but without $\mathrm{N}_{2}$-fixation the $\mathrm{N}^{*}$ distribution is unrealistic. This does however indicate that the remineralization parameterization will affect the magnitude of the basinwide nitrogen fixation signal, so the processes are not independent. In the absence of boundary condition effects, the $\mathrm{N}^{*}$ anomalies in the NOFIX run should sum to zero over the entire model domain. However, because we have maintained the relaxation to nutrient 
climatologies we expect some influences from, for example, the Mediteranean Sea outflow, which is represented in the model through nutrient relaxation to a positive $\mathrm{N}^{*}$ anomaly at the Straits of Gibraltar. This outflow probably contributes to the positive $\mathrm{N}^{*}$ anomaly at depth in Fig. 14, and it clearly influences the $\mathrm{N}^{*}$ distribution further east (not shown). We note here as an aside that representing this outflow is important to the basinwide $\mathrm{N}^{*}$ pattern, and that not including the outflow would result in an overestimation of the Atlantic Basin nitrogen fixation signal, i.e., much higher rates of $\mathrm{N}_{2}$ fixation would have to be invoked to reproduce the observed $\mathrm{N}^{*}$ anomalies without the positive $\mathrm{N}^{*}$ source from the Straits of Gibraltar.

\subsection{Sensitivity of $\mathrm{N}^{*}$ to remineralization length scale}

A number of simulations were performed to examine the sensitivity of the modeled $\mathrm{N}^{*}$ and $\mathrm{N}_{2}$-fixation rate to the remineralization length scale, which is set by the sinking rate $\left(w_{s}\right)$ and the remineralization rate $\left(e_{\mathrm{DX}}\right)$ of detritus. (As we discussed in Sect. 2.1, in our model the sinking rate is assumed to be same for $D_{N}, D_{P}$ and $D_{F e}$, whereas the remineralization rates are different with $e_{\mathrm{DP}}>e_{\mathrm{DFe}}>e_{\mathrm{DN}}$. Thus, the differences in the remineralization length scales are dictated by differences in the detritus remineralization rates.) Specifically, in these sensitivity runs we varied the phosphorus remineralization rate so that $\mathrm{D}_{\mathrm{P}}$ remineralizes between 1 and 3.5 times faster than nitrogen (In the NSTAR run the remineralization rate of $\mathrm{D}_{\mathrm{P}}$ is set so that phosphorus remineralizes 2.5 times faster than nitrogen). One consequence of changing the phosphorus recycling rate is that it changes the availability of phosphorus in the surface water, which alters the nitrogen fixation rate between the runs. Figure 15a shows the results of the sensitivity experiments; as the phosphorus remineralization scale is lengthened, nitrogen fixation rate decreases, and the subsurface maximum $\mathrm{N}^{*}$ decreases. To remove the effect of the variability in the source of nitrogen, we also plot the $\mathrm{N}^{*}$ maxima normalized to the basin averaged $\mathrm{N}_{2}$-fixation rate. The normalized $\mathrm{N}^{*}$ maximum is relatively constant across the range of different remineralization length scales, except for the simulation where nitrogen and phosphorus remineralization length scales are set equal to $400 \mathrm{~m}$. In this simulation, nitrogen fixation rates are quite low, and are below a level that can maintain a subsurface $\mathrm{N}^{*}$ maximum. These sensitivity runs reveal the tight coupling between the phosphorus remineralization length scale, and the nitrogen fixation rate. Because nitrogen fixation is phosphorus limited over much of the subtropical gyre, the phosphorus remineralization length scale sets the nitrogen fixation rate and ultimately determines the intensity of the $\mathrm{N}^{*}$ signal. In addition, Fig. $15 \mathrm{~b}$ shows that the maximum $\mathrm{N}^{*}$ value at $52^{\circ} \mathrm{W}$ is tightly correlated with annual nitrogen fixation rate averaged over the entire basin $\left(r^{2}=0.99\right)$. This tight correlation suggests that the relationship between maximum $\mathrm{N}^{*}$ in vertical sections and basin averaged nitrogen fixation
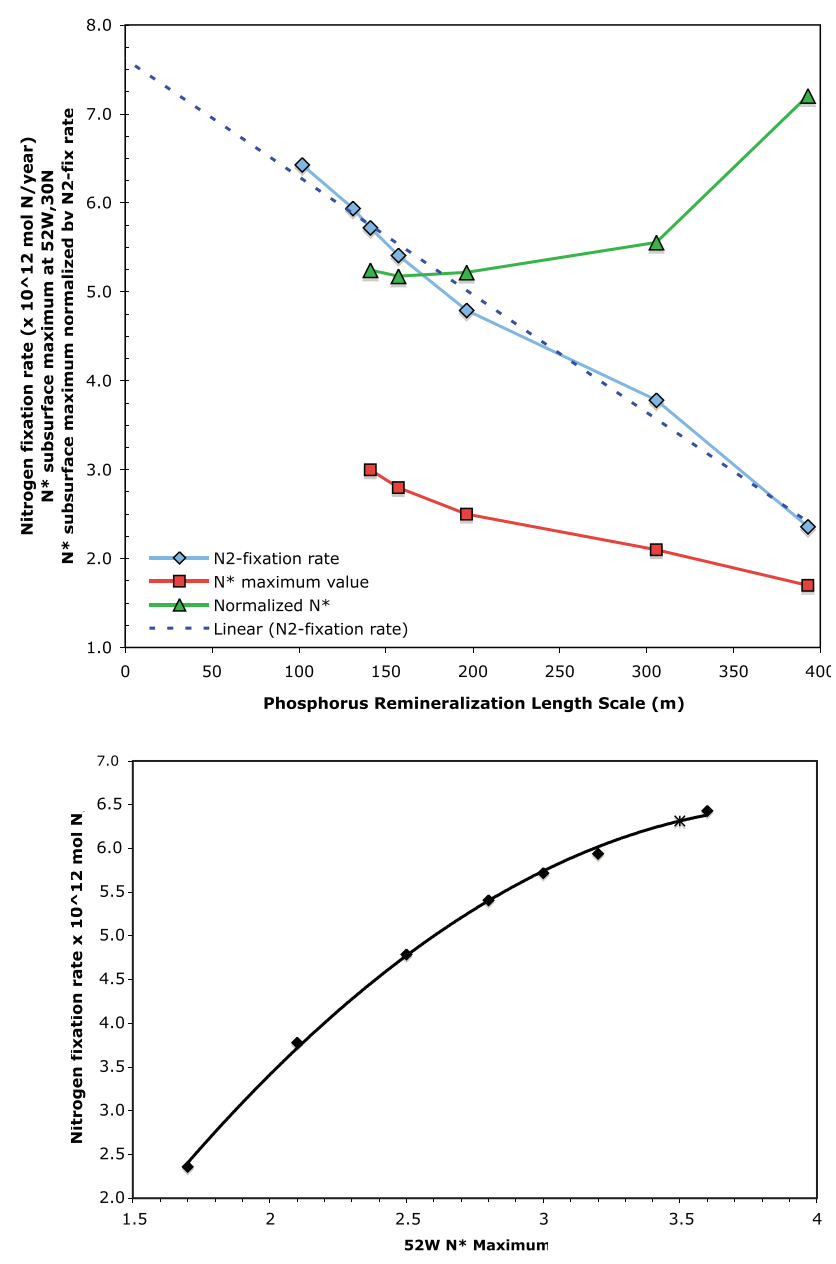

Fig. 15. (a) Sensitivity experiments to phosphorus remineralization length scale. Blue symbols show basin averaged nitrogen fixation rate, red symbols show maximum subsurface $\mathrm{N}^{*}$ values at $20^{\circ} \mathrm{N}$, $52^{\circ} \mathrm{W}$, green symbols show $\mathrm{N}^{*}$ normalized by the basin averaged nitrogen fixation rate. (b) Simulated relationship between $\mathrm{N}^{*}$ maximum at $20^{\circ} \mathrm{N}, 52^{\circ} \mathrm{W}$, and basin averaged nitrogen fixation rate.

rate can be exploited to directly estimate the nitrogen fixation rate based on observed $\mathrm{N}^{*}$.

\subsection{Nitrogen fixation and export rates}

$\mathrm{N}_{2}$-fixation is important because of its role as an $\mathrm{N}$ source in the oceanic fixed nitrogen budget (GS97; Codispoti et al., 2001; Gruber and Sarmiento, 2002; Codispoti, 2007 ??; Gruber 2007), and also because of its potential to drive a net carbon export (Hood et al., 2000). Here, we compare basin wide estimates of nitrogen fixation derived from our NSTAR run with previous observational and model based estimates for a domain that extends from $10^{\circ}-30^{\circ} \mathrm{N}$ (following GS97) and also over our entire model domain. In addition we estimate the potential carbon sink associated with this source of new nitrogen to the tropical North Atlantic. 
Table 1. Basin wide nitrogen fixation rates from the NSTAR run. These are computed over the domain of GS97 (10 $\left.-30^{\circ} \mathrm{N}\right)$ and also over the entire North Atlantic for the NSTAR run. For comparison we include previous estimates of the basin wide $\mathrm{N}_{2}$-fixation rate in the Atlantic from: 1) prognostic model runs tuned to observed Trichodesmium biomass and GS97 rates (Coles et al. 2004); 2) geochemical estimates based on observed N* anomalies (GS97, Hansell et al. 2004) and carbon drawdown (Lee et al. 2002); and 3) observational estimates based on direct rate measurements (Capone et al. 2005).

\begin{tabular}{|c|c|c|}
\hline Source & $10^{12} \mathrm{~mol} \mathrm{~N} /$ year & Notes \\
\hline \multicolumn{3}{|r|}{ Tropical Atlantic Domain, $10^{\circ} \mathrm{N}-30^{\circ} \mathrm{N}$} \\
\hline $\begin{array}{l}\text { NSTAR run } \\
\text { (this paper) }\end{array}$ & 1.8 & This study: tuned to observed $\mathrm{N}^{*}$ distribution \\
\hline $\begin{array}{l}\text { NSTAR run } \\
\text { (this paper) }\end{array}$ & 2.8 & This study: surface nitrogen fixation integrated over the northern hemisphere only. \\
\hline Coles et al. (2004) & 0.55 & Tuned to surface Trichodesmium biomass observations \\
\hline Coles et al. (2004) & 2.15 & Tuned to GS97 $\mathrm{N}^{*}$ rate estimates \\
\hline Hansell et al. (2004) & 0.31 & $\begin{array}{l}\text { Geochemically based, excludes Gulf of Mexico, and assumes smaller volumes for } \\
\text { active } \mathrm{N}_{2} \text {-fixation. }\end{array}$ \\
\hline GS97 & 2.0 & Based on observed $\mathrm{N}^{*}$, using an N:P ratio for diazotrophs of 125. \\
\hline GS97 & 3.2 & $\begin{array}{l}\text { Based on observed } \mathrm{N}^{*} \text {, but using an } \mathrm{N}: \mathrm{P} \text { ratio for diazotrophs of } 45 \text { (from Capone } \\
\text { et al., 2005). }\end{array}$ \\
\hline Capone et al. (2005) & $1.6-2.4$ & Extrapolated from surface $\mathrm{N}_{2}$-fixation rate measurements \\
\hline \multicolumn{3}{|r|}{ Whole Atlantic Domain } \\
\hline NSTAR run & 3.4 & This study: Tuned to $\mathrm{N}^{*}$ maximum \\
\hline Capone et al. (2005) & $5.5-8.7$ & Isotopic $\mathrm{N}$ calculation \\
\hline Lee et al. (2002) & 2.0 & Carbon inventory \\
\hline
\end{tabular}

Table 1 shows the NSTAR run $\mathrm{N}_{2}$-fixation rate estimate for GS97 $\left(1.8 \times 10^{12} \mathrm{~mol} \mathrm{Nyr}^{-1}\right)$. It should be noted, however, that a substantially lower N:P ratio (45) was assumed in the NSTAR run compared to the high value (125) used in the GS97 calculation. When the GS97 rate estimate is recalculated using an N:P of 45 a much higher basin wide rate is obtained $\left(3.2 \times 10^{12} \mathrm{~mol} \mathrm{~N} \mathrm{yr}^{-1}\right)$ that is not consistent with our NSTAR run estimate for the GS97 domain (Capone et al., 2005). As we discussed in Sect. 3.1.4, the $\mathrm{N}^{*}$ anomaly that accumulates at depth on isopycnal surfaces in the North Atlantic bears little relation to the pattern of $\mathrm{N}_{2}$-fixation at the surface. It is more appropriate then to integrate the surface nitrogen fixation over a larger domain that contributes to the subsurface signal. If we assume that the equator acts as a barrier to the surface advection of diazotrophically fixed nitrogen, then the $\mathrm{N}_{2}$-fixation rate that gives rise to the North Atlantic $\mathrm{N}^{*}$ signal in the model is substantially larger $\left(2.8 \times 10^{12} \mathrm{~mol} \mathrm{~N} / \mathrm{yr}\right)$ and is closer though still low relative to the recalculated GS97 estimate that is derived when an N:P ratio of 45 is used (Table 1). Thus, it appears that our modelgenerated rate estimate is consistent, after all, with GS97 as long as we account for the fact that contributions to the $\mathrm{N}^{*}$ anomaly can be derived from $\mathrm{N}_{2}$-fixation that happens over a much larger domain than $10^{\circ} \mathrm{N}-30^{\circ} \mathrm{N}$. In general, these results support the idea that the GS97 rate estimate significantly underestimates the basin wide $\mathrm{N}_{2}$-fixation rate in the north Atlantic (and also globally) because the N:P ratio used in the calculation is too high (Capone et al. 2005).
Our model-estimated basin wide $\mathrm{N}_{2}$-fixation rate derived by tuning to the observed $\mathrm{N}^{*}$ is $\sim 2.5 \mathrm{X}$ higher than our previous rate estimates derived by tuning to Trichodesmium biomass (Coles et al., 2004). We now attribute this difference to significant underestimation of diazotroph biomass, i.e., the simulated Trichodesmium colony concentrations were, in many regions, much too low and the biomass variability was too strongly seasonal with $\mathrm{N}_{2}$-fixation dropping to nearly zero in winter even at low latitudes (Hood et al., 2004). In addition, contributions from other diazotrophic species were ignored. The major advantage of tuning to $\mathrm{N}^{*}$ is that, presumably, $\mathrm{N}_{2}$-fixation inputs from all potential sources are included, even if they are not occurring at exactly the right times and places. Note that the Capone et al. (2005) rate estimate for the $10^{\circ} \mathrm{N}-30^{\circ} \mathrm{N}$ domain is comparable to our new model-derived estimate. These higher rates are now emerging from direct measurements of $\mathrm{N}_{2}$-fixation because recent surveys have, indeed, revealed higher and more seasonally persistent rates of $\mathrm{N}_{2}$-fixation and because inputs from other diazotrophic species are now being accounted for. Our rate estimate is also substantially higher than that of Hansell et al. (2004) largely because they assumed that significant $\mathrm{N}_{2}$ fixation occurs over a much smaller area of the Atlantic than is simulated by our model. As we have shown, contributions to the $\mathrm{N}^{*}$ anomaly in the western north Atlantic are derived from a much larger area that includes substantial contributions from the eastern side of the basin and the tropics. Finally, we note that the $\mathrm{N}_{2}$-fixation rate estimates derived from 
our $\mathrm{N}^{*}$-tuned model for the entire Atlantic domain are nearly double the GS97 estimate (Table 1), but still lower than rate estimates derived from nitrogen isotope ratios (Capone et al., 2005). Again, these results suggest that current geochemical estimates of Atlantic (and therefore global) $\mathrm{N}_{2}$-fixation (GS97,2002; Gruber, 2007) may be too low.

In terms of carbon, we can estimate export production for the NSTAR run by integrating the total nitrogen export out of the euphotic zone and converting to carbon units using a $\mathrm{C}: \mathrm{N}$ ratio of 106:16 (i.e., assuming that all export is derived from phytoplankton-based carbon fixation). This gives $1.16 \times 10^{15} \mathrm{gC} \mathrm{yr}^{-1}$ for our entire Atlantic model domain $\left(62^{\circ} \mathrm{N}-20^{\circ} \mathrm{S}\right)$. This falls between estimates based on nutrient uptake $\left(0.58 \times 10^{15} \mathrm{gC} \mathrm{yr}^{-1}\right.$ from Louanchi and $\mathrm{Na}$ jjar, 2000, for the domain $66^{\circ} \mathrm{N}-10^{\circ} \mathrm{S}$, adjusted following Lee, 2001) and estimates based on carbon inventories $\left(1.5 \times 10^{15} \mathrm{gC} \mathrm{yr}^{-1}\right.$ from Lee (2001), adjusted by using $2 / 3$ of the $40^{\circ} \mathrm{N}-40^{\circ} \mathrm{S}$ production to bring the range closer to that of our model domain). All of these are significantly less than the export flux estimate of Laws et al. (2000) $\left(7.4 \times 10^{15} \mathrm{gC} \mathrm{yr}^{-1}\right.$, but note that this is for the entire Atlantic).

If we convert the NSTAR run total $\mathrm{N}_{2}$-fixation rate to carbon units using a C:N ratio of 106:16 (i.e., assuming that the new nitrogen input ultimately fuels phytoplankton-based carbon fixation) it gives $0.27 \times 10^{15} \mathrm{gC} \mathrm{yr}^{-1}$, which is $23 \%$ of the total export production integrated annually for the NSTAR run (Table 1). Thus, our model results indicate that $\mathrm{N}_{2}$-fixation fuels a significant fraction of the export production in the Atlantic $\left(62^{\circ} \mathrm{N}-20^{\circ} \mathrm{S}\right)$. This result is consistent with similar estimates reported in Karl et al. (1997), Capone et al. (1997) and Coles et al. (2004).

\section{Summary and conclusions}

The focus of this study has been on incorporating phosphorus and iron limitations into a model with an explicit dynamic representation of $\mathrm{N}_{2}$-fixation. Although this study focuses more on the process of nitrogen fixation and its role in basin wide biogeochemistry, it is important to note that the model reproduces reasonable surface chlorophyll patterns as compared with satellite-derived distributions, as well as reasonably good agreement with surface and subsurface nitrogen, phosphorus and iron distributions. In terms of nutrient limitation, the model reproduces a co-limitation of diazotroph growth rate by phosphorus and iron in the tropics as observed by Mills et al. (2004) and iron limitation of primary productivity during the spring bloom in the central (temperate) North Atlantic as demonstrated by Moore et al. (2006).

Iron is of particular interest given the recent emphasis on modeling iron biogeochemistry in marine systems. The representation employed here is very simple, and similar to prior efforts (e.g., Christian et al., 2002; Moore et al., 2002b, 2004, 2006; Dutkiewicz et al., 2005; Parekh et al., 2005; Moore and Doney, 2007). One modest change involves the addition of surface atmospheric fluxes of iron to the detrital iron pool rather than to the dissolved iron pool. This is necessary to maintain low surface iron concentrations with a sharp subsurface ferrocline that has been observed in direct measurements off of the west coast of Africa in high Fe/dust deposition regions (Measures and Landing, unpublished observations, see Anderson and Henderson, 2005; Bergquist and Boyle, 2006). This model also maintains reasonable iron concentrations at depth without setting an arbitrary concentration for ligand bound dissolved iron that is not scavenged.

We find that our model can reproduce subsurface $\mathrm{N}^{*}$ distributions with reasonable, though relatively high rates of surface $\mathrm{N}_{2}$-fixation. One important conclusion of this study is that surface nitrogen fixation is not co-located with subsurface gradients in $\mathrm{N}^{*}$. Rather, the fixed nitrogen is advected far from its source prior to generating a subsurface $\mathrm{N}^{*}$ anomaly. We conclude that subsurface $\mathrm{N}^{*}$ distributions cannot be used to infer where surface nitrogen fixation occurs, except on very broad (i.e., basin wide) scales. It should be noted, however, that the model misses certain aspects of the subsurface $\mathrm{N}^{*}$ anomaly. In general, the maximum $\mathrm{N}^{*}$ anomaly in the model is deposited somewhat too deeply. There is also some evidence in the observed $\mathrm{N}^{*}$ distributions of sinks for $\mathrm{N}^{*}$ perhaps associated with African or South American continental shelf denitrification, which are not included the model. The model also has a rather poor representation of the boundary between thermocline water with southern and northern sources, and as a result, tends to advect the northern hemisphere $\mathrm{N}^{*}$ signal too far to the south and east into the Gulf of Guinea.

Modeling the subsurface $\mathrm{N}^{*}$ distribution is particularly challenging because it involves simulating not only the magnitude and time-space pattern of the surface $\mathrm{N}_{2}$-fixation rate, but also the relative remineralization length scales of nitrogen and phosphorus in the context of advection and diffusion in 3 dimensions. Our sensitivity studies reveal that changes in the phosphorus remineralization rate (relative to nitrogen) linearly determine the surface nitrogen fixation rate. Without enhanced phosphorus remineralization (relative to nitrogen) the basin averaged nitrogen fixation rate is very modest, and cannot sustain the observed subsurface $\mathrm{N}^{*}$ maximum. Phosphorus remineralization rate has to be increased by about a factor of 2 (relative to nitrogen) to allow high enough rates of $\mathrm{N}_{2}$-fixation to sustain subsurface $\mathrm{N}^{*}$ anomalies that are comparable to the observations. We also show that the magnitude of the subsurface $\mathrm{N}^{*}$ anomaly is tightly related to the basin averaged $\mathrm{N}_{2}$-fixation rate, which provides a potential means for estimating the basin averaged rate using observed $\mathrm{N}^{*}$ anomalies

The $10^{\circ} \mathrm{N}-30^{\circ} \mathrm{N} \mathrm{N}_{2}$-fixation rate generated by the model when it is tuned to $\mathrm{N}^{*}\left(\sim 1.8 \times 10^{12}\right.$ moles $\left.\mathrm{N} \mathrm{yr}^{-1}\right)$ is comparable to geochemical estimates derived from observed N* anomalies (GS97; Gruber and Sarmiento, 2002; Gruber, 2006) even though these geochemical estimates assume 
a much higher $\mathrm{N}: \mathrm{P}$ ratio for diazotrophs. When a more reasonable $\mathrm{N}: \mathrm{P}$ ratio is adopted the geochemical estimates give much higher rates $\left(3.2 \times 10^{12}\right.$ moles $\mathrm{N} \mathrm{yr}^{-1}$, Capone et al., 2005). Our model generates comparably high rates $\left(2.8 \times 10^{12}\right.$ moles $\left.\mathrm{Nyr}^{-1}\right)$ when we integrate over the entire North Atlantic domain. We therefore suggest that current geochemical estimates of $\mathrm{N}_{2}$-fixation rate in the North Atlantic include contributions from diazotrophs that occur well outside of the area of integration (i.e., $10^{\circ} \mathrm{N}-30^{\circ} \mathrm{N}$ ), which is consistent with our finding that the fixed nitrogen is advected far from its source prior to generating a subsurface $\mathrm{N}^{*}$ anomaly. Furthermore, these findings indicate that current geochemical estimates substantially underestimate $\mathrm{N}_{2}$-fixation rates in the Atlantic. We calculate a total of $3.4 \times 10^{12}$ moles $\mathrm{N} \mathrm{yr}^{-1}$ of $\mathrm{N}_{2}$-fixation from $25^{\circ} \mathrm{S}-65^{\circ} \mathrm{N}$, which supports $23 \%$ of the new production in the Atlantic.

A recent study by Deutsch et al. (2007) uses surface nutrient excursions from the Redfield Ratio to estimate the global nitrogen fixation rate. They assume that any reduction in the high $\mathrm{P}: \mathrm{N}$ ratio created in open ocean denitrification zones must be due to nitrogen fixation once the effects of advection and diffusion are removed. They find lower rates of nitrogen fixation in the Atlantic compared with earlier studies based on subsurface $\mathrm{N}^{*}$ anomalies (GS97), or direct measurements (Capone et al., 2005). Most of the global nitrogen fixation in their study occurs in the Pacific adjacent to denitrification zones. Some issues however are unresolved in this study. The Atlantic imports low $\mathrm{N}^{*}$ water from the Arctic, and $\mathrm{N}^{*}$ is low or negative across the entire South Atlantic basin at $30^{\circ} \mathrm{S}$, yet there is a large positive $\mathrm{N}^{*}$ anomaly in the North Atlantic subtropical gyre, as seen in this study. This high N:P anomaly must be generated locally. Secondly, observations of high nitrogen fixation rates and diazotroph biomass have been measured across the North and South Atlantic (see data compilation in Hood et al, 2004; as well as other recent results, e.g., Mills et al, 2005, Tyrell et al, 2003). These direct observations of diazotrophs and nitrogen fixation in waters with very low to undetectable surface inorganic phosphorus concentrations suggest that nitrogen fixation is not as completely dependent on high P:N ratios as the model of Deutsch et al. (2007) would suggest.

If we scale our northern hemisphere Atlantic estimate of nitrogen fixation globally following GS97 (i.e., multiply $2.8 \times 10^{12}$ by a factor of 4 ), then we obtain a global rate on the order of $11 \times 10^{12}$ moles $\mathrm{Nyr}^{-1}$. These nitrogen fixation rate estimates are based on our efforts to reproduce observed $\mathrm{N}^{*}$ anomalies in the Atlantic and should therefore include a representation of all $\mathrm{N}_{2}$-fixation sources. This is less than half of the recently revised global denitrification rate $\left(28 \times 10^{12}\right.$ moles $\left.\mathrm{N} \mathrm{yr}^{-1}\right)$ estimated by Codispoti (2007). However, if we scale global estimates of shelf denitrification $\left(21 \times 10^{12}\right.$ moles $\mathrm{Nyr}^{-1}$, Codispoti, 2007), by the fraction of global shelf area in the North Atlantic $(\sim 10 \%)$, then shelf denitrification in the North Atlantic could be as high as $2.1 \times 10^{12}$ moles $\mathrm{Nyr}^{-1}$, or nearly as high as our open ocean nitrogen fixation estimate. This estimate is consistent with the recent results of Fennel et al. (2006) who suggest rates of $2.3 \times 10^{12}$ moles $\mathrm{Nyr}^{-1}$ for the North Atlantic shelf. Because our results suggest that the N:P anomalies associated with nitrogen fixation can be advected far from source regions before they emerge in the dissolved inorganic pools at depth, it is possible that our "net" estimate of Atlantic (and thus global) nitrogen fixation underestimates the total rate by $50 \%$. 


\section{Appendix A}

\section{Biogeochemical model equations}

In this appendix we provide the specific model equations along with brief definitions of the terms. The reader is referred to Sect. 2 for a general description of the model.

The phytoplankton equation includes terms for growth, mortality, and grazing;

$\frac{\partial \mathrm{P}}{\partial t}=\alpha U_{\mathrm{P}} \mathrm{P}-s_{\mathrm{P}} \mathrm{P}-h_{\mathrm{P}} C_{M} H \mathrm{P}$

where growth is modeled with co-limitation of light and nutrient availability;

$U_{P}=\mu_{\mathrm{P}} e^{-I / I_{\beta} \mathrm{P}}\left(1-e^{-I / I_{\mathrm{P}}}\right)$

$\left[\min \left(\frac{\mathrm{DIN}}{\mathrm{DIN}+\mathrm{PKS}_{\mathrm{N}}}, \frac{\mathrm{DIP}}{\mathrm{DIP}+\mathrm{PKS}_{\mathrm{P}}}, \frac{\mathrm{DIFe}}{\mathrm{DIFe}+\mathrm{PKS}_{\mathrm{Fe}}}\right)\right]$

The Trichodesmium equation includes growth, mortality, and grazing;

$\frac{\partial T}{\partial t}=\alpha G_{T} T-s_{T} T-h_{T} C_{M} H T$

here growth is a function of light limitation and phosphorus or iron limitations;

$G_{T}=\mu_{T}\left(1-e^{-I / I_{T}}\right)\left[\min \left(\frac{\mathrm{Ph}}{\mathrm{Ph}+\mathrm{TKS}_{\mathrm{P}}}, \frac{\mathrm{DIFe}}{\mathrm{DIFe}+\mathrm{TKS}_{\mathrm{Fe}}}\right)\right]$

$\mathrm{Ph}=\max (\mathrm{DIP}, \mathrm{DOP})$ under the assumption that diazotrophs can take up DOP as well as DIP.

The heterotroph equation includes grazing on other compartments, as well as itself;

$$
\begin{aligned}
& \frac{\partial H}{\partial t}=\mathrm{R}_{\mathrm{HF}}\left(g e_{\mathrm{DON}} h_{\mathrm{DON}} C_{M} H \mathrm{DON}\right. \\
& \quad+g e_{D} h_{D} C_{M} H D_{N}+g e_{\mathrm{P}} h_{\mathrm{P}} C_{M} H \mathrm{P} \\
& \left.\quad+g e_{T} h_{T} C_{M} H T+g e_{H} h_{H} C_{M} H^{2}\right)-h_{H} C_{M} H^{2}
\end{aligned}
$$

where $\mathrm{R}_{\mathrm{HF}}$ expresses the most limiting nutrient in available prey for heterotrophs;

$\mathrm{R}_{\mathrm{HF}}=\min \left(\frac{\mathrm{R}_{\mathrm{NNF}}}{\mathrm{R}_{\mathrm{NNH}}}, \frac{\mathrm{R}_{\mathrm{PNF}}}{\mathrm{R}_{\mathrm{PNH}}}, \frac{\mathrm{R}_{\mathrm{FeNF}}}{\mathrm{R}_{\mathrm{FeNH}}}\right)$
$\mathrm{R}_{\mathrm{NNF}}=\frac{\mathrm{DON}+D_{N}+\mathrm{P}+H+T}{\mathrm{DON}+D_{\mathrm{N}}+\mathrm{P}+H+T}=1$
$\mathrm{R}_{\mathrm{PNF}}=\frac{\mathrm{DOP}+D_{P}+\mathrm{R}_{\mathrm{PNP}} \mathrm{P}+\mathrm{R}_{\mathrm{PNH}} H+\mathrm{R}_{\mathrm{PNT}} T}{\mathrm{DON}+D_{N}+\mathrm{P}+H+T}$

$\mathrm{R}_{\mathrm{FeNF}}=\frac{\mathrm{DOFe}+D_{\mathrm{Fe}}+\mathrm{R}_{\mathrm{FeNP}} \mathrm{P}+\mathrm{R}_{\mathrm{FeNH}} H+\mathrm{R}_{\mathrm{FeNT}} T}{\mathrm{DON}+D_{\mathrm{N}}+\mathrm{P}+H+T}$

and prey preference is expressed as;

$h_{\mathrm{DON}}=\Phi_{\mathrm{DON}} / \Theta$

$h_{D}=\Phi_{D} / \Theta$

$h_{\mathrm{P}}=\Phi_{\mathrm{P}} / \Theta$

$h_{T}=\Phi_{T} / \Theta$

$h_{H}=\Phi_{H} / \Theta$

with;

$\Theta=\Phi_{\mathrm{DON}} \mathrm{DON}+\Phi_{D} \mathrm{D}+\Phi_{\mathrm{P}} \mathrm{P}+\Phi_{T} \mathrm{~T}+\Phi_{H} \mathrm{H}+\mathrm{HKS}$ 
Table A1. Model parameters.

\begin{tabular}{|c|c|c|c|c|}
\hline Description & Symbol & Value & Units & Source \\
\hline Growth efficiency for $\mathrm{H}$ on $\mathrm{P}$ & $g e_{\mathrm{P}}$ & 0.2 & Dimensionless & Hood et al. (2001) \\
\hline Assimilation efficiency for $\mathrm{H}$ on $\mathrm{P}$ & $a e_{\mathrm{P}}$ & 0.7 & Dimensionless & Hood et al. (2001) \\
\hline Growth efficiency for $\mathrm{H}$ on $\mathrm{D}$ & $g e_{D}$ & 0.2 & Dimensionless & Hood et al. (2001) \\
\hline Assimilation efficiency for $\mathrm{H}$ on $\mathrm{D}$ & $a e_{D}$ & 0.7 & Dimensionless & Hood et al. (2001) \\
\hline Growth efficiency for $\mathrm{H}$ on $\mathrm{T}$ & $g e_{T}$ & 0.2 & Dimensionless & Hood et al. (2001) \\
\hline Assimilation efficiency for $\mathrm{H}$ on $\mathrm{T}$ & $a e_{T}$ & 0.7 & Dimensionless & Hood et al. (2001) \\
\hline Growth efficiency for $\mathrm{H}$ on DON & $g e_{\mathrm{DON}}$ & 0.2 & Dimensionless & Hood et al. (2001) \\
\hline Assimilation efficiency for $\mathrm{H}$ on DON & $a e_{\mathrm{DON}}$ & 1.0 & Dimensionless & Hood et al. (2001) \\
\hline Heterotrophic max. consumption rate & $C_{M}$ & 6.4 & $\mathrm{~d}^{-1}$ & Hood et al. (2001) \\
\hline Heterotrophic saturation constant & $H K S$ & 0.8 & $\mathrm{mmol} \mathrm{m}^{-3}$ & Hood et al. (2001) \\
\hline Heterotrophic preference for $\mathrm{P}$ & $\Phi_{\mathrm{P}}$ & 0.4286 & Dimensionless & Hood et al. (2004) \\
\hline Heterotrophic preference for $\mathrm{D}$ & $\Phi_{\mathrm{D}}$ & 0.0 & Dimensionless & Hood et al. (2004) \\
\hline Heterotrophic preference for $\mathrm{H}$ & $\Phi_{\mathrm{H}}$ & 0.2857 & Dimensionless & Hood et al. (2004) \\
\hline Heterotrophic preference for $\mathrm{T}$ & $\Phi_{\mathrm{T}}$ & 0.05 & Dimensionless & Hood et al. (2004) \\
\hline Heterotrophic preference for DON & $\Phi_{\mathrm{DON}}$ & 0.2175 & Dimensionless & Hood et al. (2004) \\
\hline Maximum phytoplankton growth rate & $\mu_{P}$ & 3.22 & $\mathrm{~d}^{-1}$ & Hood et al. (2001) \\
\hline Maximum Trichodesmium growth rate & $\mu_{T}$ & 0.23 & $d^{-1}$ & See below ${ }^{1}$ \\
\hline Phytoplankton natural mortality rate & $s_{P}$ & 0.05 & $d^{-1}$ & Hood et al. (2001) \\
\hline Trichodesmium natural mortality rate & $s_{T}$ & 0.01 & $\mathrm{~d}^{-1}$ & See below ${ }^{2}$ \\
\hline Partitioning of $\mathrm{P}$ and $\mathrm{T}$ senescence & $\beta$ & 0.25 & Dimensionless & Hood et al. (2001) \\
\hline Partitioning of $\mathrm{P}$ and $\mathrm{T}$ production & $\alpha$ & 0.7 & Dimensionless & Hood et al. (2001) \\
\hline Phytoplankton light saturation param. & $I_{P}$ & 30 & Watts $\mathrm{m}^{-2}$ & See below ${ }^{3}$ \\
\hline $\mathrm{T}$ light saturation parameter & $I_{T}$ & 70 & Watts $\mathrm{m}^{-2}$ & See below ${ }^{4}$ \\
\hline Partitioning of excretion to DIN & $\gamma$ & 0.75 & Dimensionless & Hood et al. (2001) \\
\hline P photoinhibition parameter & $I_{\beta \mathrm{P}}$ & 400 & Watts $\mathrm{m}^{-2}$ & Hood et al. (2001) \\
\hline $\mathrm{N}: \mathrm{N}$ ratio for $\mathrm{H}$ & $R_{\mathrm{NNH}}$ & 1 & Dimensionless & See below 5 \\
\hline $\mathrm{P}: \mathrm{N}$ ratio for $\mathrm{H}$ & $R_{\mathrm{PNH}}$ & 0.0625 & Dimensionless & Redfield et al. (1963) \\
\hline Fe: $\mathrm{N}$ ratio for $\mathrm{H}$ & $R_{\mathrm{FeNH}}$ & $3.75 \times 10^{-5}$ & Dimensionless & See below 6 \\
\hline$P: N$ ratio for $T$ & $R_{\mathrm{PNT}}$ & 0.02222 & Dimensionless & See below ${ }^{7}$ \\
\hline $\mathrm{Fe}: \mathrm{N}$ ratio for $\mathrm{T}$ & $R_{\mathrm{FeNT}}$ & $2.236 \times 10^{-4}$ & Dimensionless & See below ${ }^{8}$ \\
\hline $\mathrm{P}: \mathrm{N}$ ratio for $\mathrm{P}$ & $R_{\mathrm{PNP}}$ & 0.0625 & Dimensionless & Redfield et al. (1963) \\
\hline $\mathrm{Fe}: \mathrm{N}$ ratio for $\mathrm{P}$ & $R_{\mathrm{FeNP}}$ & $2.981 \times 10^{-5}$ & Dimensionless & See below ${ }^{9}$ \\
\hline Sat. const. for DIN uptake by $\mathrm{P}$ & $\mathrm{PKS}_{\mathrm{N}}$ & 0.5 & $\mathrm{mmol} \mathrm{m}^{-3}$ & Hood et al. (2001) \\
\hline Sat. const. for DIN uptake by $\mathrm{T}$ & $\mathrm{TKS}_{\mathrm{N}}$ & 0.5 & $\mathrm{mmol} \mathrm{m}^{-3}$ & Hood et al. 2001 \\
\hline Sat. const. for DIP uptake by $\mathrm{P}$ & $P K S_{\mathrm{P}}$ & 0.0030 & $\mathrm{mmol} \mathrm{m}^{-3}$ & See below ${ }^{12}$ \\
\hline Sat. const. for DIP uptake by $\mathrm{T}$ & $\mathrm{TKS}_{p}$ & 0.0077 & $\mathrm{mmol} \mathrm{m}^{-3}$ & See below ${ }^{10}$ \\
\hline Sat. const. for DIFe uptake by $\mathrm{P}$ & $\mathrm{PKS}_{\mathrm{Fe}}$ & $1.0 \times 10^{-5}$ & $\mathrm{mmol} \mathrm{m}^{-3}$ & See below ${ }^{11}$ \\
\hline Sat. const. for DIFe uptake by $\mathrm{T}$ & $\mathrm{TKS}_{\mathrm{Fe}}$ & $1.0 \times 10^{-4}$ & $\mathrm{mmol} \mathrm{m}^{-3}$ & See below 13 \\
\hline Fe scavenging rate constant & $K_{\mathrm{Fe}}$ & $12.5 \times 10^{-5}$ & $d^{-1}$ & See below ${ }^{14}$ \\
\hline Enhanced $D_{P}$ recycling rate & $e_{D P}$ & 0.35 & $\mathrm{~d}^{-1}$ & See below 15 \\
\hline Enhanced DOP recycling rate & $e_{\mathrm{DOP}}$ & 0.14 & $\mathrm{~d}^{-1}$ & See below ${ }^{16}$ \\
\hline Enhanced $D_{N}$ recycling rate & $e_{D N}$ & 0.14 & $d^{-1}$ & See below ${ }^{17}$ \\
\hline Enhanced DON recycling rate & $e_{\mathrm{DON}}$ & 0.14 & $\mathrm{~d}^{-1}$ & See below ${ }^{18}$ \\
\hline Enhanced $D_{\mathrm{Fe}}$ recycling rate & $e_{\mathrm{DFe}}$ & 0.35 & $\mathrm{~d}^{-1}$ & See below 19 \\
\hline Enhanced DOFe recycling rate & $e_{\mathrm{DOFe}}$ & 0.14 & $\mathrm{~d}^{-1}$ & See below ${ }^{20}$ \\
\hline Sinking rate of Detritus & $w_{S S}$ & 12.0 & meters $\mathrm{d}^{-1}$ & See below 21 \\
\hline Iron solubility & $\mathrm{Fe}_{\mathrm{SOL}}$ & 0.01 & $\mathrm{~d}^{-1}$ & See below ${ }^{22}$ \\
\hline $\mathrm{Fe}$ fraction in dust & $\mathrm{Fe}_{\%}$ & 0.035 & Dimensionless & See below 23 \\
\hline
\end{tabular}

${ }^{1}$ Equivalent to a doubling time of $\sim 3$ days, from Capone et al. (1997).

2 Increased slightly from $.025 \mathrm{~d}^{-1}$ in Hood et al. (2004) to maintain Trichodesmium colony concentrations in the western tropical and subtropical Altantic that are consistent with those observed there by Carpenter and Romans (1991).

3,4 Decreased from 40 and 80 Watts $\mathrm{m}^{-2}$, respectively, in Hood et al. (2001) to compensate for deeper mixed layers generated by HYCOM.

5 Equals 1 by definition. Included for clarity in Eq. (A6).

${ }^{6}$ Derived from Fe:C=7.5 ( $\mu$ mole:mole) for heterotrophic bacteria from Tortell et al. (1999) using a C:N ratio of 32:6.4 (mole:mole) from Vrede et al. (2002).

7 D. G. Capone, personal communication (2004).

${ }^{8}$ Derived using Trichodesmium Fe colony ${ }^{-1}$ (median $=$

8 pmol Fe colony $^{-1}$ ) and $\mathrm{N}_{\text {colony }}{ }^{-1}$ (median $=32 \mu \mathrm{mol} \mathrm{N}$ colony $^{-1}$ ) from Sañudo-Wilhelmy et al. (2001).

${ }^{9}$ Using Fe:C = 4.5 ( $\left.\mu \mathrm{mol}: \mathrm{mol}\right)$ for phytoplankton from Fung et al. (2000) and assuming a Redfield C:N = 106:16.

${ }^{10}$ Mean from J. Sohm personal communication (2004), unpublished kinetic studies on Trichodesmium in Atlantic waters.

${ }^{11}$ From Christian et al. (2002), assuming phytoplankton in the model are dominated by small forms.

12 Assuming half saturation constants for $\mathrm{P}$ uptake are similar for phytoplankton and Trichodesmium.

${ }^{13}$ Assuming half saturation constants for Fe uptake are similar for Trichodesmium and phytoplankton, following Moore et al. (2002a).

14 Set a posteriori to give best fit to published Fe profiles in the Wu et al. (2000) and Measures and Landing, unpublished data; see Fig. 1 in Anderson and Henderson, (2005).

15,16 Set a posteriori to relieve $\mathrm{P}$ limitation and provide reasonable near-surface DIP concentrations.

17,18 Applied to ensure $\mathrm{D}_{\mathrm{N}}$ and DON remineralization at depth.

19,20 Applied to ensure $\mathrm{D}_{\mathrm{Fe}}$ and DOFe remineralization at depth and adjusted to reproduce observed deep Fe profiles from Wu et al. (2000) and Measures and Landing, unpublished data; see Fig. 1 in Anderson and Henderson (2005).

21 Set a posteriori to give reasonable near-surface DIN, DIP and DIFe concentrations.

22 Values typically assumed to be between 1 and 10\% of the Fe in dust soluble/bioavailable, cf., Moore et al. (2002a); Christian et al. (2002); Duce and Tindale (1991).

23 Following Christian et al. (2002). 
The dissolved inorganic nitrogen equation includes terms for phytoplankton and diazotroph uptake, excretion from food uptake as well as from food that was unusable due to stoichiometry, and inputs from remineralization of dissolved and particulate material;

$$
\begin{aligned}
& \frac{\partial \mathrm{DIN}}{\partial t}=-U_{\mathrm{P}} \mathrm{P}-G_{T} T+\mathrm{R}_{\mathrm{HF}} \gamma\left(\left(a e_{\mathrm{DON}}-g e_{\mathrm{DON}}\right) h_{\mathrm{DON}} C_{M} H \mathrm{DON}\right. \\
& +\left(a e_{D}-g e_{D}\right) h_{D} C_{M} H D_{N}+\left(a e_{\mathrm{P}}-g e_{\mathrm{P}}\right) h_{\mathrm{P}} C_{M} H \mathrm{P} \\
& \left.+\left(a e_{T}-g e_{T}\right) h_{T} C_{M} H T+\left(a e_{H}-g e_{H}\right) h_{H} C_{M} H^{2}\right) \\
& +X_{\mathrm{HF}} \gamma\left(a e_{\mathrm{DON}} h_{\mathrm{DON}} C_{M} H \mathrm{DON}+a e_{D} h_{D} C_{M} H t D_{\mathrm{N}}+a e_{\mathrm{P}} h_{\mathrm{P}} C_{M} H \mathrm{P}\right. \\
& \left.+a e_{T} h_{T} C_{M} H T+a e_{H} h_{H} C_{M} H^{2}\right)+e_{\mathrm{DON}} \mathrm{DON}+e_{D N} D_{N}
\end{aligned}
$$

where;

$$
X_{\mathrm{HF}}=\max \left(0,1 .-\mathrm{R}_{\mathrm{HF}}\right)
$$

and uptake by diazotrophs is limited by DIN;

$U_{T}=\mu_{T}\left(1-e^{-I / I_{T}}\right)\left[\min \left(\frac{\mathrm{DIN}}{\mathrm{DIN}+\mathrm{TKS}_{\mathrm{N}}}, \frac{\mathrm{DIPh}}{\mathrm{DIPh}+\mathrm{TKS}_{\mathrm{P}}}, \frac{\mathrm{DIFe}}{\mathrm{DIFe}+\mathrm{TKS}_{\mathrm{Fe}}}\right)\right]$

The dissolved inorganic phosphorus equation follows the DIN equation except for the diazotroph uptake, which may be from the DOP pool if DOP concentrations are higher than DIP concentrations;

$$
\begin{aligned}
& \frac{\partial \mathrm{DIP}}{\partial t}=\mathrm{R}_{\mathrm{PNH}} \mathrm{R}_{\mathrm{HF}} \gamma\left(\left(a e_{\mathrm{DON}}-g e_{\mathrm{DON}}\right) h_{\mathrm{DON}} C_{M} H \mathrm{DON}+\left(a e_{D}-g e_{D}\right) h_{D} C_{M} H D_{\mathrm{N}}\right. \\
& \left.+\left(a e_{\mathrm{P}}-g e_{\mathrm{P}}\right) h_{\mathrm{P}} C_{M} H \mathrm{P}+\left(a e_{T}-g e_{T}\right) h_{T} C_{M} H T+\left(a e_{H}-g e_{H}\right) h_{H} C_{M} H^{2}\right) \\
& +X_{\mathrm{HFP}} \gamma\left(a e_{\mathrm{DON}} h_{\mathrm{DON}} C_{M} H \mathrm{DON}+a e_{D} h_{D} C_{M} H D_{\mathrm{N}}+a e_{\mathrm{P}} h_{\mathrm{P}} C_{M} H \mathrm{P}\right. \\
& \left.+a e_{T} h_{T} C_{M} H T+a e_{H} h_{H} C_{M} H^{2}\right)-\mathrm{R}_{\mathrm{PNP}} U_{P} \mathrm{P}-\overbrace{\mathrm{R}_{\mathrm{PNT}} G_{T} T}^{\mathrm{DIP}>=\mathrm{DOP}}+e_{\mathrm{DOP}} \mathrm{DOP}+e_{D P} D_{\mathrm{P}}
\end{aligned}
$$

where;

$X_{\mathrm{HFP}}=\mathrm{R}_{\mathrm{PNF}}-\left(\mathrm{R}_{\mathrm{HF}} \mathrm{R}_{\mathrm{PNH}}\right)$

The dissolved inorganic iron equation again follows DIP, but with an additional scavenging term;

$$
\begin{aligned}
& \frac{\partial \mathrm{DIFe}}{\partial t}=\mathrm{R}_{\mathrm{FeNH}} \mathrm{R}_{\mathrm{HF}} \gamma\left(\left(a e_{\mathrm{DON}}-g e_{\mathrm{DON}}\right) h_{\mathrm{DON}} C_{M} H \mathrm{DON}+\left(a e_{D}-g e_{D}\right) h_{D} C_{M} H D_{N}\right. \\
& \left.+\left(a e_{\mathrm{P}}-g e_{\mathrm{P}}\right) h_{\mathrm{P}} C_{M} H P+\left(a e_{T}-g e_{T}\right) h_{T} C_{M} H T+\left(a e_{H}-g e_{H}\right) h_{H} C_{M} H^{2}\right) \\
& +X_{\mathrm{HFFe}} \gamma\left(a e_{\mathrm{DON}} h_{\mathrm{DON}} C_{M} H \mathrm{DON}+a e_{D} h_{D} C_{M} H D_{N}+a e_{\mathrm{P}} h_{\mathrm{P}} C_{M} H \mathrm{P}\right. \\
& \left.+a e_{T} h_{T} C_{M} H T+a e_{H} h_{H} C_{M} H^{2}\right)-\mathrm{R}_{\mathrm{FeNP}} U_{\mathrm{PP}} \mathrm{P}-\mathrm{R}_{\mathrm{FeNT}} G_{T} T-S_{\mathrm{KVG}}+e_{\mathrm{DOFe}} \mathrm{DOFe} \\
& +e_{\mathrm{DFe}} D_{\mathrm{Fe}}
\end{aligned}
$$

where;

$X_{\mathrm{HFFe}}=\mathrm{R}_{\mathrm{FeNF}}-\left(\mathrm{R}_{\mathrm{HF}} \mathrm{R}_{\mathrm{FeNH}}\right)$

and scavenging is represented as;

$S_{\mathrm{KVG}}=-K_{\mathrm{Fe}}\left[1+k\left(D_{N}+D_{\mathrm{P}}+D_{\mathrm{Fe}}\right)\right] \mathrm{DIFe}$

where $k$ is an arbitrary constant that doubles scavenging at high detrital concentrations. 
The dissolved organic nitrogen equation includes terms for excretion following the DIN equation, as well as inputs from mortality and growth of phytoplankton and diazotrophs and losses from remineralization;

$$
\begin{aligned}
& \frac{\partial \mathrm{DON}}{\partial t}=\mathrm{R}_{\mathrm{HF}}(1-\gamma)\left(\left(a e_{\mathrm{DON}}-g e_{\mathrm{DON}}\right) h_{\mathrm{DON}} C_{M} H \mathrm{DON}+\left(a e_{D}-g e_{D}\right) h_{D} C_{M} H D_{\mathrm{N}}\right. \\
& \left.+\left(a e_{\mathrm{P}}-g e_{\mathrm{P}}\right) h_{\mathrm{P}} C_{M} H \mathrm{P}+\left(a e_{T}-g e_{T}\right) h_{T} C_{M} H T+\left(a e_{H}-g e_{H}\right) h_{H} C_{M} H^{2}\right) \\
& +X_{\mathrm{HFN}}(1-\gamma)\left(a e_{\mathrm{DON}} h_{\mathrm{DON}} C_{M} H \mathrm{DON}+a e_{D} h_{D} C_{M} H D_{\mathrm{N}}+a e_{\mathrm{P}} h_{\mathrm{P}} C_{M} H \mathrm{P}\right. \\
& \left.+a e_{T} h_{T} C_{M} H T+a e_{H} h_{H} C_{M} H^{2}\right)+(1-\beta) s_{\mathrm{P}} \mathrm{P}+(1-\beta) s_{T} T+(1-\alpha) U_{\mathrm{PP}} \\
& +(1-\alpha) G_{T} T-h_{\mathrm{DON}} C_{M} H \mathrm{DON}-e_{\mathrm{DON}} \mathrm{DON}
\end{aligned}
$$

The dissolved organic phosphorus equation follows the DON equation, but includes an uptake term for diazotrophy in cases where DOP concentrations exceed DIP;

$$
\begin{aligned}
& \frac{\partial \mathrm{DOP}}{\partial t}=\mathrm{R}_{\mathrm{PNH}} \mathrm{R}_{\mathrm{HF}}(1-\gamma)\left(\left(a e_{\mathrm{DON}}-g e_{\mathrm{DON}}\right) h_{\mathrm{DON}} C_{M} H \mathrm{DON}\right. \\
& +\left(a e_{D}-g e_{D}\right) h_{D} C_{M} H D_{N}+\left(a e_{\mathrm{P}}-g e_{\mathrm{P}}\right) h_{\mathrm{P}} C_{M} H \mathrm{P}+\left(a e_{T}-g e_{T}\right) h_{T} C_{M} H T \\
& \left.+\left(a e_{H}-g e_{H}\right) h_{H} C_{M} H^{2}\right)+X_{\mathrm{HFP}}(1-\gamma)\left(a e_{\mathrm{DON}} h_{\mathrm{DON}} C_{M} H \mathrm{DON}+a e_{D} h_{D} C_{M} H D_{\mathrm{N}}\right. \\
& \left.+a e_{\mathrm{P}} h_{\mathrm{P}} C_{M} H \mathrm{P}+a e_{T} h_{T} C_{M} H T+a e_{H} h_{H} C_{M} H^{2}\right)+R_{\mathrm{PNP}}(1-\beta) s_{\mathrm{P}} \mathrm{P} \\
& +R_{\mathrm{PNT}}(1-\beta) s_{T} T+R_{\mathrm{PNP}}(1-\alpha) U_{\mathrm{PP}}+\mathrm{R}_{\mathrm{PNT}}(1-\alpha) G_{T} T-\overbrace{\mathrm{R}_{\mathrm{PNT}} G_{T} T}^{\mathrm{OP}>h_{\mathrm{DON}} C_{M} H \mathrm{DOP}} \\
& -e_{\mathrm{DOP}} \mathrm{DOP}
\end{aligned}
$$

The dissolved organic iron equation follows the DON equation;

$$
\begin{aligned}
& \frac{\partial \mathrm{DOFe}}{\partial t}=\mathrm{R}_{\mathrm{FeNH}} \mathrm{R}_{\mathrm{HF}}(1-\gamma)\left(\left(a e_{\mathrm{DON}}-g e_{\mathrm{DON}}\right) h_{\mathrm{DON}} C_{M} H \mathrm{DON}\right. \\
& +\left(a e_{D}-g e_{D}\right) h_{D} C_{M} H D_{N}+\left(a e_{\mathrm{P}}-g e_{\mathrm{P}}\right) h_{\mathrm{P}} C_{M} H \mathrm{P}+\left(a e_{T}-g e_{T}\right) h_{T} C_{M} H T \\
& \left.+\left(a e_{H}-g e_{H}\right) h_{H} C_{M} H^{2}\right)+X_{\mathrm{HFFe}}(1-\gamma)\left(a e_{\mathrm{DON}} h_{\mathrm{DON}} C_{M} H \mathrm{DON}+a e_{D} h_{D} C_{M} H D_{\mathrm{N}}\right. \\
& \left.+a e_{\mathrm{P}} h_{\mathrm{P}} C_{M} H \mathrm{P}+a e_{T} h_{T} C_{M} H T+a e_{H} h_{H} C_{M} H^{2}\right)+\mathrm{R}_{\mathrm{FeNP}}(1-\beta) s_{\mathrm{P}} \mathrm{P} \\
& +\mathrm{R}_{\mathrm{FeNT}}(1-\beta) s_{T} T+\mathrm{R}_{\mathrm{FeNP}}(1-\alpha) U_{\mathrm{P}} \mathrm{P}+\mathrm{R}_{\mathrm{FeNT}}(1-\alpha) G_{T} T-h_{\mathrm{DON}} C_{M} H \mathrm{DOFe} \\
& -e_{\mathrm{DOFe}} \mathrm{DOFe}
\end{aligned}
$$

The N-detritus equation includes terms for egestion, as well as mortality, and losses from remineralization, grazing, and sinking;

$$
\begin{aligned}
& \frac{\partial D_{N}}{\partial t}=\mathrm{R}_{\mathrm{HF}}\left(\left(1-a e_{\mathrm{DON}}\right) h_{\mathrm{DON}} C_{M} H \mathrm{DON}+\left(1-a e_{D}\right) h_{D} C_{M} H D_{N}\right. \\
& \left.+\left(1-a e_{\mathrm{P}}\right) h_{\mathrm{P}} C_{M} H \mathrm{P}+\left(1-a e_{T}\right) h_{T} C_{M} H T+\left(1-a e_{H}\right) h_{H} C_{M} H^{2}\right) \\
& +X_{\mathrm{HF}}\left(\left(1-a e_{\mathrm{DON}}\right) h_{\mathrm{DON}} C_{M} H \mathrm{DON}+\left(1-a e_{D}\right) h_{D} C_{M} H D_{N}\right. \\
& \left.+\left(1-a e_{\mathrm{P}}\right) h_{\mathrm{P}} C_{M} H \mathrm{P}+\left(1-a e_{T}\right) h_{T} C_{M} H T+\left(1-a e_{H}\right) h_{H} C_{M} H^{2}\right)+\beta S_{\mathrm{P}} \mathrm{P} \\
& +\beta s_{T} T-e_{D N} D_{\mathrm{N}}-h_{D} C_{M} H D_{\mathrm{N}}-w_{S} D_{N}
\end{aligned}
$$

where

$w_{s}=\min \left(75 ., \max \left(w_{s s}, D_{N} * 4444+10.555\right)\right)$

which provides a linear ramp from $15 \mathrm{~m} /$ day to $75 \mathrm{~m} / \mathrm{d}$, increasing as a function of detrital concentration; 
The P-detritus equation follows the N-detritus equation;

$$
\begin{aligned}
& \frac{\partial D_{P}}{\partial t}=\mathrm{R}_{\mathrm{PNH}} \mathrm{R}_{\mathrm{HF}}\left(\left(1-a e_{\mathrm{DON}}\right) h_{\mathrm{DON}} C_{M} H \mathrm{DON}+\left(1-a e_{D}\right) h_{D} C_{M} H D_{\mathrm{N}}\right. \\
& \left.+\left(1-a e_{\mathrm{P}}\right) h_{\mathrm{P}} C_{M} H \mathrm{P}+\left(1-a e_{T}\right) h_{T} C_{M} H T+\left(1-a e_{H}\right) h_{H} C_{M} H^{2}\right) \\
& +X_{\mathrm{HFP}}\left(\left(1-a e_{\mathrm{DON}}\right) h_{\mathrm{DON}} C_{M} H \mathrm{DON}+\left(1-a e_{D}\right) h_{D} C_{M} H D_{N}\right. \\
& \left.+\left(1-a e_{\mathrm{P}}\right) h_{\mathrm{P}} C_{M} H \mathrm{P}+\left(1-a e_{T}\right) h_{T} C_{M} H T+\left(1-a e_{H}\right) h_{H} C_{M} H^{2}\right)+R_{\mathrm{PNP}} \beta s_{\mathrm{P}} \mathrm{P} \\
& +\mathrm{R}_{\mathrm{PNT}} \beta s_{T} T-e_{D P} D_{P}-h_{D} C_{M} H D_{\mathrm{P}}-w_{S} D_{\mathrm{P}}
\end{aligned}
$$

The Fe-detritus equation also follows the $\mathrm{N}$-detritus equation;

$$
\begin{aligned}
& \frac{\partial D_{\mathrm{Fe}}}{\partial t}=\mathrm{R}_{\mathrm{FeNH}} \mathrm{R}_{\mathrm{HF}}\left(\left(1-a e_{\mathrm{DON}}\right) h_{\mathrm{DON}} C_{M} H \mathrm{DON}+\left(1-a e_{D}\right) h_{D} C_{M} H D_{\mathrm{N}}\right. \\
& \left.+\left(1-a e_{\mathrm{P}}\right) h_{\mathrm{P}} C_{M} H \mathrm{P}+\left(1-a e_{T}\right) h_{T} C_{M} H T+\left(1-a e_{H}\right) h_{H} C_{M} H^{2}\right) \\
& +X_{\mathrm{HFFe}}\left(\left(1-a e_{\mathrm{DON}}\right) h_{\mathrm{DON}} C_{M} H \mathrm{DON}+\left(1-a e_{D}\right) h_{D} C_{M} H D_{\mathrm{N}}\right. \\
& \left.+\left(1-a e_{\mathrm{P}}\right) h_{\mathrm{P}} C_{M} H \mathrm{P}+\left(1-a e_{T}\right) h_{T} C_{M} H T+\left(1-a e_{H}\right) h_{H} C_{M} H^{2}\right)+R_{\mathrm{FeNP}} \beta s_{\mathrm{P}} \mathrm{P} \\
& +\mathrm{R}_{\mathrm{FeNT}} \beta s_{T} T-e_{\mathrm{DFe}} D_{\mathrm{Fe}}-h_{D} C_{M} H D_{\mathrm{Fe}}-w_{S} D_{\mathrm{Fe}}+\mathrm{Fe}_{\mathrm{SOL}} \mathrm{Fe}_{\%} \mathrm{DST}
\end{aligned}
$$

where DST is dust deposition rate.

Acknowledgements. We would like to thank S. W. A. Naqvi, J. Montoya and M. Voss for inviting us to participate in the SPOT ON conference and for encouraging us to contribute to this special issue. We also thank L. A. Codispoti for numerous stimulating discussions on the global nitrogen cycle, and J. Montoya for assistance with validating North Atlantic nitrogen fixation. This work was supported by NSF grants OCE-9981218 and OCE-0527040, NASA grant NAG5-12749 and NOAA grant NA17EC1483. This is UMCES Contribution 4109.

Edited by: J. Middelburg

\section{References}

Ammerman, J. W., Hood, R. R., Case, D. A., and Cotner, J. B.: Phosphorus deficiency in the Atlantic: An emerging paradigm in Oceanography, EOS 84, 165-170, 2003.

Anderson, R. F. and Henderson, G. M.: GEOTRACES A global study of the marine biogeochemical cycles of trace elements and their isotopes, Oceanography, 18, 76-79, 2005.

Bates, N. R. and Hansell, D. A.: Temporal variability of excess nitrate in the Subtropical Mode Water of the North Atlantic Ocean, Mar. Chem., 84, 225-241, 2004.

Bergquist, B. A. and Boyle, E. A.: Dissolved iron in the tropical and subtropical Atlantic Ocean, Global Biogeochem. Cy., 20, GB1015, doi:10.1029/2004GB0025405, 2006.

Bleck, R.: An oceanic general circulation model framed in hybrid isopycnic-cartesian coordinates, Ocean Model., 4, 55-88, 2002.

Bowie, A. R., Whitworth, D. J., Achterberg, E. P., Mantoura, R. F. C., and Worsfold, P. J.: Biogeochemistry of Fe and other trace el- ements (Al, Co, Ni) in the upper Atlantic Ocean, Deep-Sea Res. I, 49, 605-636, 2002.

Broecker, W. S.: Keeping global change honest, Global Biogeochem. Cy., 5, 191-192, 1991.

Capone, D. G., Burns, J. A., Montoya, J. P., Michaels, A. F., Subramaniam, A., Carpenter, E. J.: Nitrogen fixation by Trichodesmium spp.: An important source of new nitrogen to the tropical North Atlantic Ocean, Global Biogeochem. Cy., 19, GB2024, doi:10.1029/2004GB002331, 2005.

Capone, D. G., Zehr, J. P., Paerl, H. W., Bergman, B., and Carpenter, E. J.: Trichodesmium: a globally significant marine cyanobacterium, Science, 276, 1221-1229, 1997.

Carpenter, E. J. and Romans, K.: Major role of the cyanobacterium Trichodesmium in nutrient cycling in the North Atlantic Ocean, Science, 254, 1356-1358, 1991.

Chassignet, E. P., Smith, L. T., Halliwell, G. R., and Bleck, R.: North Atlantic simulation with the HYbrid Coordinate Ocean Model (HYCOM): Impact of the vertical coordinate choice, reference density, and thermobaricity, J. Phys. Oceanogr., 33, 2504 2526, 2003.

Christian, J. R., Verschell, M. A., Murtugudde, R., Busalacchi, A. J., and McClain, C. R.: Biogeochemical modeling of the tropical Pacific Ocean. II: Iron biogeochemistry, Deep-Sea Res. II, 49, 545-565, 2002b.

Codispoti, L., Brandes, J. A., Christensen, J., Devol, A., Naqvi, S., Paerl, H. W., and Yoshinari, T.: The oceanic fixed nitrogen and nitrous oxide budgets: Moving targets as we enter the anthropocene?, Scientia Marina (Barcelona), 65, suppl. 2, 85-105, 2001.

Codispoti, L.: An oceanic fixed nitrogen sink exceeding $400 \mathrm{Tg} \mathrm{N}$ a_1 vs the concept of homeostasis in the fixed-nitrogen inventory, Biogeosciences, 4, 233-253, 2007, 
http://www.biogeosciences.net/4/233/2007/.

Coles, V. J., Hood, R. R., Pascual, M., and Capone, D. G.: Modeling the effects of Trichodesmium and nitrogen fixation in the Atlantic Ocean, J. Geophys. Res., 109, C06007, doi:06010.01029/02002JC001754, 2004.

Conkright, M. E., Levitus, S., and Boyer, T. P.: World Ocean Atlas 1994, Volume 1: Nutrients. NOAA Atlas NESDIS 1. U.S. Department of Commerce, NOAA, NESDIS, Silver Spring, MD, 1994.

Croot, P. L., Streu, P., and Baker, A. R.: Short residence time for iron in surface seawater impacted by atmospheric dry deposition from Saharan dust events, Geophys. Res. Lett., 31, doi:10.1029/2004GL020153, 2004.

da Silva, A., Young, A. C., and Levitus, S.: Atlas of Surface Marine Data, Vol. 1, Algorithms and Procedures, National Oceanic and Atmospheric Administration, Silver Spring, MD, 1994.

Davis, C. S. and McGillicuddy, D. J.: Transatlantic abundance of the $\mathrm{N}_{2}$-fixing colonial cyanobacterium Trichodesmium, Science, 312, 1517-1520, 2006.

Del Vecchio, R. and Subramaniam, A.: Influence of the Amazon River on the surface optical properties of the western tropical North Atlantic Ocean, J. Geophys. Res., 109, C11001, doi:10.1029/2004JC002503, 2004.

Deutsch, C., Sarmiento, J. L., Sigman, D. M., Gruber, N., and Dunne, J. P.: Spatial coupling of nitrogen inputs and losses in the ocean, Nature, 455, doi:10.1038 163-167, 2007.

Doney, S. C.: Ocean Carbon and Climate Change (OCCC): An Implementation Strategy for U.S. Carbon Science Scientific Steering Group (CCSSG) and Inter-agency Working Group (CCIWG), Washington D.C., 108 pp., 2004.

Duce, R. A. and Tindale, N. W.: Atmospheric transport of iron and its deposition in the ocean, Limnol. Oceanogr., 36, 1715-1726, 1991.

Dutkiewicz, S., Follows, M. J., and Parekh, P.: Interactions of the iron and phosphorus cycles: A three-dimensional model study, Global Biogeochem. Cy., 19(1), GB1021, doi:10.1029/2004GB002342, 2005.

Dyhrman, S. T., Chappell, P. D., Haley, S. T., Moffett, J. W., Orchard, E. D., Waterbury, J. B., and Webb, E. A.: Phosphonate utilization by the globally important marine diazotroph Trichodesmium, Nature, 439, 68-71, 2006.

Fennel, K., Spitz, Y. H., Letelier, R. M., Abbott, M. R., and Karl, D. M.: A deterministic model for $\mathrm{N}_{2}$-fixation at stn. ALOHA in the subtropical North Pacific Ocean, Deep-Sea Res. II, 49, 149-174, 2002

Fung, I. Y., Meyn, S. K., Tegen, I., Doney, S. C., John, J. G., Bishop, J. K. B.: Iron supply and demand in the upper ocean, Global Biogeochem. Cyc., 14, 281-295, 2000.

Gruber, N. and Sarmiento, J. L.: Global patterns of marine nitrogen fixation and denitrification, Global Biogeochem. Cy., 11, 235266, 1997.

Gruber, N. and Sarmiento, J. L.: Large scale biogeochemicalphysical interactions in elemental cycles, in: The Sea, edited by: Robinson, A. R., McCarthy, J. J., Rothschild, B. J., John Wiley, New York, 337-399, 2002.

Gruber, N.: The marine nitrogen cycle: Overview of distributions and processes, in: Nitrogen in the Marine Environment, 2nd Edition, edited by: Carpenter, E. J., Capone, D. G., Bronk, D. A., and Mulholland, M. R., Elsevier, 2007, in press.
Halliwell, G. R.: Evaluation of vertical coordinate and vertical mixing algorithms in the HYbrid Coordinate Ocean Model (HYCOM), Ocean Model., 7, 285-322, 2004.

Hansell, D. A., Bates, N. R., and Olson, D. B.: Excess nitrate and nitrogen fixation in the Subtropical North Atlantic, Mar. Chem. 84, 243-265, 2004.

Herñandez-León, S., Postel, L., Arístegui, J., Gómez, M., Frenanda Montero, M., Torres, S., Almeida, C., Kuhner, E., Brenning, U., and Hagen, E.: Large-scale and mesoscale distribution of plankton biomass and metabolic activity in the northeastern central Atlantic, J. Oceanogr., 55, 471-482, 1999.

Hood, R. R., Bates, N. R., Capone, D. G., and Olson, D. B.: Modeling the effect of nitrogen fixation on carbon and nitrogen fluxes at BATS, Deep-Sea Res. II, 48, 1609-1648, 2001.

Hood, R. R., Coles, V. J., and Capone, D. G.: Modeling the distribution of Trichodesmium and nitrogen fixation in the Atlantic Ocean, J. Geophys. Res., 109, C06006, doi:10.1029/2002JC001753, 2004.

Hood, R. R., Laws, E. A., Armstrong R. A., Bates N. R., Brown C. W., Carlson C. A., Chai F., Doney S. C., Falkowski P.G., Feely R.A., Friedrichs M.A.M., Landry M.R., Moore J.K., Nelson D.M., Richardson T.L., Salihoglu B., Schartau M., Toole D.A., Wiggert J.D.: Pelagic functional group modeling: Progress, challenges and prospects, Deep-Sea Res. II, 53, 459-512, 2006.

Hood, R. R., Michaels, A. F., and Capone, D. G.: Answers sought to the enigma of marine nitrogen fixation, EOS, 81, 133, 138-139, 2000.

Karl, D. M., Letelier, R., Hebel, D. V., Bird, D. F., and Winn, C. D.: Trichodesmium blooms and new nitrogen in the North $\mathrm{Pa}-$ cific gyre, in: Marine Pelagic Cyanobacteria: Trichodesmium and other Diazotrophs, edited by: Carpenter, E. J., Capone, D. G., and Reuter, J. G., Kluwer Academic Publishers, Boston, 219237, 1992.

Karl, D. M., Letelier, R., Tupas, L., Dore, J., Christian, J., and Hebel, D.: The role of nitrogen fixation in biogeochemical cycling in the subtropical North Pacific Ocean, Nature, 388, 533538, 1997.

Key, R. M., Kozyr, A., Sabine, C. L., Lee, K., Wanninkhof, R., Bullister, J., Feely, R. A., Millero, F., Mordy, C., and Peng, T. H.: A global ocean carbon climatology: Results from GLODAP, Global Biogeochem. Cy., 18, BG4031, doi:10.1029/2004GB002247, 2004.

Langlois, R. J., LaRoche, J., and Raab, P. A.: Diazotrophic diversity and distribution in the tropical and subtropical Atlantic ocean, Appl. Environ. Microbiol., 71, 7910-7919, 2005.

Laws, E. A., Falkowski, P. G., Smith, W. O., Ducklow, H., and McCarthy, J. J.: Temperature effects on export production in the open ocean, Global Biogeochem. Cy., 14, 1231-1246, 2000.

Lee, K.: Global net community production estimated from the annual cycle of surface water total dissolved inorganic carbon, Limnol. Oceanogr., 46, 1287-1297, 2001.

Lee, K., Karl, D. M., Waninkhof, R., and Zhang, J.-Z.: Global estimates of net carbon production in the nitrate-depleted tropical and subtropical oceans, Geophys. Res. Lett., 29, 1907, doi:1910.1029/2001GL014198, 2002.

Levitus, S. and Boyer, T. P.: World Ocean Atlas 1994, Vol. 4, Temperature, NOAA Atlas NESDIS 4, U.S. Department of Commerce, NOAA, NESDIS, Silver Spring, MD, 1994.

Levitus, S., Burgett, R., and Boyer, T. P.: World Ocean Atlas 1994, 
Vol. 3, Salinity, NOAA Atlas NESDIS 3, U.S. Department of Commerce, NOAA, NESDIS, Silver Spring, MD, 1994.

Louanchi, F. and Najjar, R. G.: A global climatology of phosphate, nitrate and silicate in the upper ocean: Spring-summer production and shallow remineralization, Global Biogeochem. Cy., 14, 957-978, 2000.

Louanchi, F. and Najjar, R. G.: Annual cycles of nutrients and oxygen in the upper layers of the North Atlantic Ocean, Deep-Sea Res. II, 48, 2155-2171, 2001.

Luo, C., Mahowald, N., and del Corral, J.: Sensitivity study of meteorological parameters on mineral aerosol mobilization, transport and distribution, J. Geophys. Res., 108(D12), 4447, doi:10.1029/2003JD0003483, 2003.

Mahowald, N. and Luo, C.: A less dusty future?, Geophys. Res. Lett., 30, 1903, doi:10.1029/2003GL017880, 2003.

Mahowald, N., Luo, C., del Corral, J., and Zender, C.: Interannual variability in atmospheric mineral aerosols from a 22-year model simulations and observational data, J. Geophys. Res., 108(D12), 4352, doi:10.1029/2002JD002821, 2003.

Martin, J. H., Knauer, G. A., Karl, D. M., and Broenkow, W. W.: VERTEX: Carbon cycling in the Northeast Pacific, Deep-Sea Res., 34, 267-285, 1987.

Michaels, A. F., Olson, D., Sarmiento, J. L., Ammerman, J. W., Fanning, K., Jahnke, R., Knap, A. H., Lipschultz, F., and Prospero, J. M.: Inputs, losses and transformations of nitrogen and phosphorus in the pelagic North Atlantic Ocean, Biogeochemistry, 35, 181-226, 1996.

Mills, M. M., Ridame, C., Davey, M., La Roche, J., and Geider, R. J.: Iron and phosphorus co-limit nitrogen fixation in the eastern tropical North Atlantic, Nature, 429, 292-294, 2004.

Moore, C. M., Mills, M. M., Milne, A., Langlois, R., Achterberg, E. P., Lochte, K., Geider, R. J., and La Roche, J.: Iron limits primary productivity during spring bloom development in the central North Atlantic, Global Change Biol., 12, 626-634, 2006a.

Moore, J. K., Doney, S. C., Glover, D. M., and Fung, I. Y.: Iron cycling and nutrient-limitation patterns in surface waters of the World Ocean, Deep-Sea Res. II, 49, 463-507, 2002 b.

Moore, J. K., Doney, S. C., Kleypas, J. A., Glover, D. M., and Fung, I. Y.: An intermediate complexity marine ecosystem model for the global domain, Deep-Sea Res. II, 49, 403-462, 2002a.

Moore, J. K., Doney, S. C., and Lindsay, K.: Upper ocean ecosystem dynamics and iron cycling in a global threedimensional model, Global Biogeochem. Cy., 18, GB4028, doi:4010.1029/2004GB002220, 2004.

Moore, J. K., Doney, S. C., Lindsay, K., Mahowald, N., and Michaels, A. F.: Nitrogen fixation amplifies the ocean biogeochemical response to decadal timescale variations in mineral dust deposition, Tellus Series B, 58(5), 560-572, $2006 \mathrm{~b}$.

Moore, J. K. and Doney, S. C.: Iron availability limits the ocean nitrogen inventory stabilizing feedbacks between marine denitrification and nitrogen fixation, Global Biogeochem. Cy., 21, GB2001, doi:10.1029/2006GB002762, 2007.

Neumann, T.: Towards a 3D-ecosystem model of the Baltic Sea, J. Mar. Syst., 25, 405-419, 2000.

Orcutt, K. M., Lipschultz, F., Gundersen, K., Anrimoto, R., Gallon, J. R., Michaels, A. F., and Knap, A. H.: A Seasonal study of the significance of $\mathrm{N}_{2}$ fixation by Trichodesmium spp. at the Bermuda Atlantic Time-Series Study (BATS), Deep-Sea Res., 48, 1583-1608, 2001.

Paerl, H. W., Prufert-Bebout, L. E., Guo, and C. Z.: Iron-stimulated $\mathrm{N}-2$ fixation and growth in natural and cultured populations of the planktonic marine cyanobacteria Trichodesmium spp., Appl. Environ. Microbiol., 60, 1044-1047, 1994.

Parekh, P., Follows, M. J., and Boyle, E. A.: Decoupling of iron and phosphate in the global ocean, Global Biogeochem. Cy., 19, GB2020, doi:10.1029/2004GB002280, 2005.

Redfield, A. C. , Ketchum, B. H., and Richard, F. A.: The influence of organisms on the composition of seawater, in: The Sea, edited by: Hill, M. N., Interscience, New York, 27-77, 1963.

Rueter, J. G.: Theoretical Fe limitations of microbial $\mathrm{N}_{2}$ fixation in the oceans, EOS, 63, 945, 1982.

Rueter, J. G., Hutchins, D. A., Smith, R. W., and Unsworth, N. L.: Iron nutrition of Trichodesmium, in: Marine Pelagic Cyanobacteria: Trichodesmium and other Diazotrophs, edited by: Carpenter, E. J., Capone, D. G., and Rueter, J. G., Kluwer Academic Publishers, Dordrecht, The Netherlands, 289-306, 1992.

Sanudo-Wilhelmy, S. A., Kustka, A. B., Gobler, C. J., Hutchins, D. A., Yang, M., Lwiza, K., Burns, J., Capone, D. G., Raven, J. A., and Carpenter, E. J.: Phosphorus limitation of nitrogen fixation by Trichodesmium in the central Atlantic Ocean, Nature, 411, 66-69, 2001.

Sarmiento, J. L. and Bender, M. L.: Carbon biogeochemistry and climate change, Photosynth. Res., 39, 209-234, 1994.

Siegel, D. A. and Deuser, W. G.: Trajectories of sinking particles in the Sargasso Sea: modeling of statistical funnels above deepocean sediment traps, Deep-Sea Res., 44, 1519-1541, 1997.

Tortell, P. D., Maldonado, M. M., Granger, J., and Price, N. M.: Marine bacteria and biogeochemical cycling of iron in the oceans, FEMS Microbiol. Ecol., 29, 1-11, 1999.

Tyrrell, T.: The relative influences of nitrogen and phosphorus on oceanic primary production, Nature, 400, 525-531, 1999.

Tyrrell, T., Marañón, E., Poulton, A., Bowie, A. R., Harbour, D. S., and Woodward, E. M. S.: Large-scale latitudinal distribution of Trichodesmium spp. in the Atlantic Ocean, J. Plankton Res., 25, 405-416, 2003.

Voss, M., Croot, P., Lochte, K., Mills, M. and Peeken, I.: Patterns of nitrogen fixation along $10 \mathrm{~N}$ in the tropical Atlantic, Geophys. Res. Let., 31, L23S09, doi:10.1029/2004GL020127, 2004.

Vrede, K., Heldal, M., Norland, S., and Bratbak, G.: Elemental composition $(\mathrm{C}, \mathrm{N}, \mathrm{P})$ and cell volume of exponentially growing and nutrient-limited bacterioplankton, Applied and Environmental Microbiology, 68(6), 2965-2971, doi:10.1128/AEM.68.6.2965-2971.2002, 2002.

Walsh, J. J. and Steidinger, K. A.: Saharan dust and Florida red tides: The cyanophyte connection, J. Geophys. Res., 106, 11 597-11 612, 2001.

Wu, J., Sunda, W., Boyle, E. A., and Karl, D. M.: Phosphate depletion in the Western North Atlantic Ocean, Science, 289, 759762, 2000.

Yamamoto-Kawai, M., Carmack, E., and McLaughlin, F.: Nitrogen balance and Arctic throughflow, Nature, 443(7107), 43-43, 2006. 